\title{
A Cost-Effective Embedded Platform for Greenhouse Environment Control and Remote Monitoring
}

\author{
Radu L. Sumalan ${ }^{1, *(\mathbb{D}, \text { Nicoleta Stroia }}{ }^{2}$, Daniel Moga ${ }^{2}$, Vlad Muresan ${ }^{2}$, Alexandru Lodin ${ }^{3}$, \\ Teodor Vintila ${ }^{4} \mathbb{C}$ and Cosmin A. Popescu ${ }^{5}$ \\ 1 Faculty of Horticulture and Forestry, Banat's University of Agricultural Sciences and Veterinary Medicine \\ "King Michael I of Romania" from Timisoara, Calea Aradului 119, 300645 Timisoara, Romania \\ 2 Faculty of Automation and Computer Science, Technical University of Cluj-Napoca, Memorandumului 28, \\ 400114 Cluj-Napoca, Romania; nicoleta.stroia@aut.utcluj.ro (N.S.); daniel.moga@aut.utcluj.ro (D.M.); \\ vlad.muresan@aut.utcluj.ro (V.M.) \\ 3 Faculty of Electronics, Telecommunications and Information Technology, Technical University of \\ Cluj-Napoca, Memorandumului 28, 400114 Cluj-Napoca, Romania; alexandru.lodin@bel.utcluj.ro \\ 4 Faculty of Animal Sciences and Bioengineering, Banat's University of Agricultural Sciences and Veterinary \\ Medicine "King Michael I of Romania" from Timisoara, Calea Aradului 119, 300645 Timisoara, Romania; \\ tvintila@animalsci-tm.ro \\ 5 Faculty of Agriculture, Banat's University of Agricultural Sciences and Veterinary Medicine “King Michael I \\ of Romania" from Timisoara, Calea Aradului 119, 300645 Timisoara, Romania; cosmin_popescu@usab-tm.ro \\ * Correspondence: sumalanagro@yahoo.com
}

Received: 3 June 2020; Accepted: 23 June 2020; Published: 29 June 2020

check for updates

\begin{abstract}
This paper presents the development of a cost-effective automatic system for greenhouse environment control. The architectural and functional features were analyzed in the context of the realization of a controlled-environment agricultural system through all its stages: installation, deployment of the software, integration, maintenance, crop control strategy setup and daily operation of the grower. The proposed embedded platform provides remote monitoring and control of the greenhouse environment and is implemented as a distributed sensing and control network integrating wired and wireless nodes. All nodes were built with low-cost, low-power microcontrollers. The key issues that were addressed include the energy-efficient control, the robustness of the distributed control network to faults and a low-cost hardware implementation. The translation of the supervisory growth-planning information to the operational (control network) level is achieved through a specific architecture residing on a crop planning module (CPM) and an interfacing block (IB). A suite of software applications with flows and interfaces developed from a grower-centric perspective was designed and implemented on a multi-tier architecture. The operation of the platform was validated through implementation of sensing and control nodes, application of software for configuration and visualization, and deployment in typical greenhouses.
\end{abstract}

Keywords: control systems; sensors; plant production in controlled environments; wireless sensor networks; embedded software

\section{Introduction}

The realization of a controlled-environment agricultural (CEA) system, as a means for improving the growth, development and quality of the crops cultivated in greenhouses is based on the deployment of appropriate automatic control systems (ACSs) able to support the environmental conditioning.

The range of solutions for ACSs dedicated to greenhouses is quite extensive. In the modeling, design and simulation of advanced control techniques there are many theoretical proposals mainly validated using simulation of greenhouse models. Few of them are validated in practical setups, 
running in greenhouses. From the implementation perspective, one can observe solutions ranging from hobbyist projects, through well-established sensing and control devices that are validated by growers, up to turnkey comprehensive climate control systems.

The last two decades brought many technological advances in affordable implementations: low-cost processors in embedded ecosystems, optimized software libraries, embedded web servers, Internet of Things, cloud platforms, long-term evolution (LTE) routers for virtual private network (VPN) and internet access. These advances all influence the solutions proposed by different companies at the levels of sensors, control modules, software platforms and remote monitoring and management [1-12].

The ultimate goal of all these approaches is to contribute to the creation of a healthy greenhouse environment that will lead to an optimal yield for a given crop. However, the real feedback about yield improvement, energy saving, return on investment and, finally, efficiency from a business point of view can come only from growers.

This paper looks at the problem of automatic greenhouse climate control from several different perspectives: the user perspective, i.e., that of the grower; the perspective of obtaining new "better" solutions, i.e., that of the research community; the perspective of development and manufacturing, i.e., that of producers of ACS devices and equipment; and the perspective of installation and maintenance, i.e., that of specialized companies. Each perspective holds specific challenges for the greenhouse ACS, challenges that are examined herein.

A cost-effective approach that is exemplified in the results section is based on the Physis embedded platform [13-16] for implementing a distributed ACS. The hardware architecture of the proposed ACS is introduced together with the suite of software applications and details on the user interaction with the system.

\section{Materials and Methods}

The design of an ACS dedicated to greenhouse control must consider several different stages: installation of the hardware, deployment of the software, integration with the communication infrastructure, maintenance and repairing and, most importantly, crop control strategy setup and daily operation and interaction of the user (grower) with the system. All these stages have specific associated actions, and their efficiency is affected by the array of features offered by the greenhouse ACS. Each desirable feature is a challenge for both the research and development (R\&D) and manufacturing processes when a cost-effective implementation is envisaged. Table 1 summarizes these challenges.

Table 1. Challenges for automatic control systems (ACSs) used in agricultural applications.

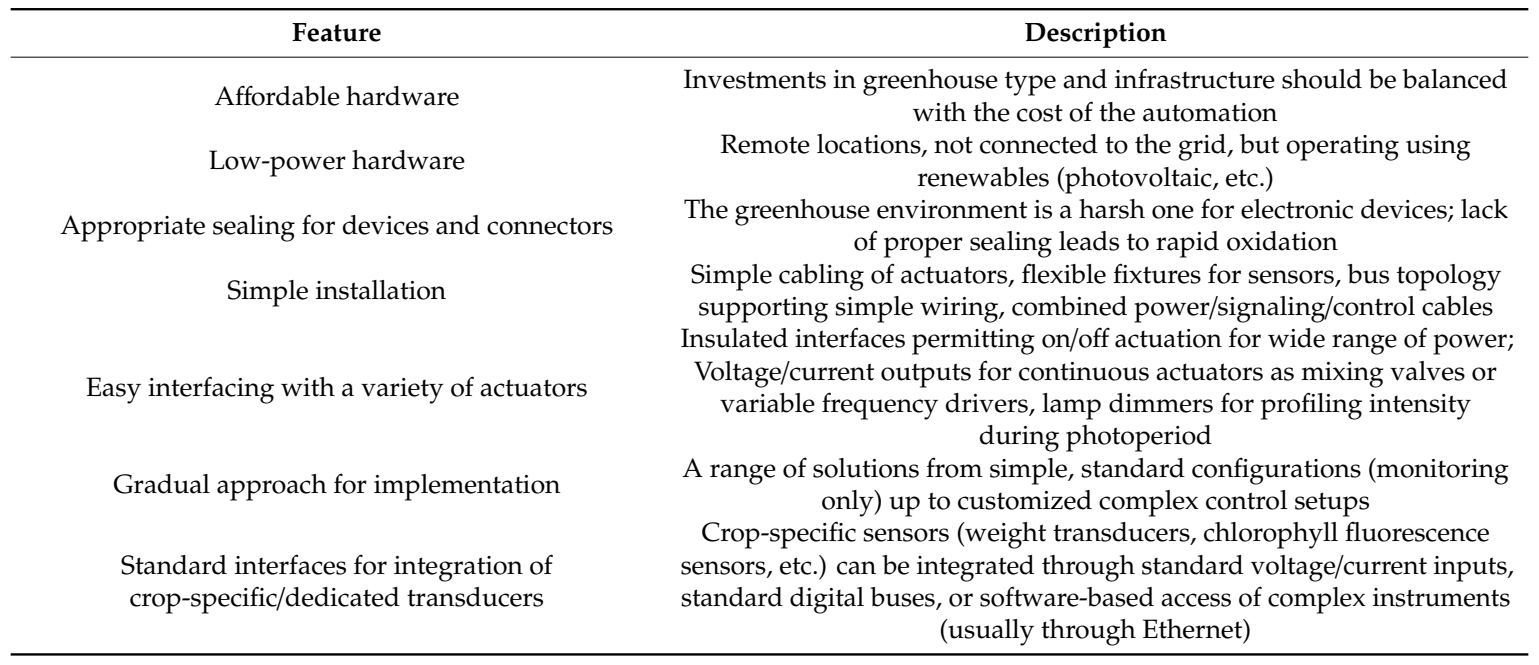


Table 1. Cont.

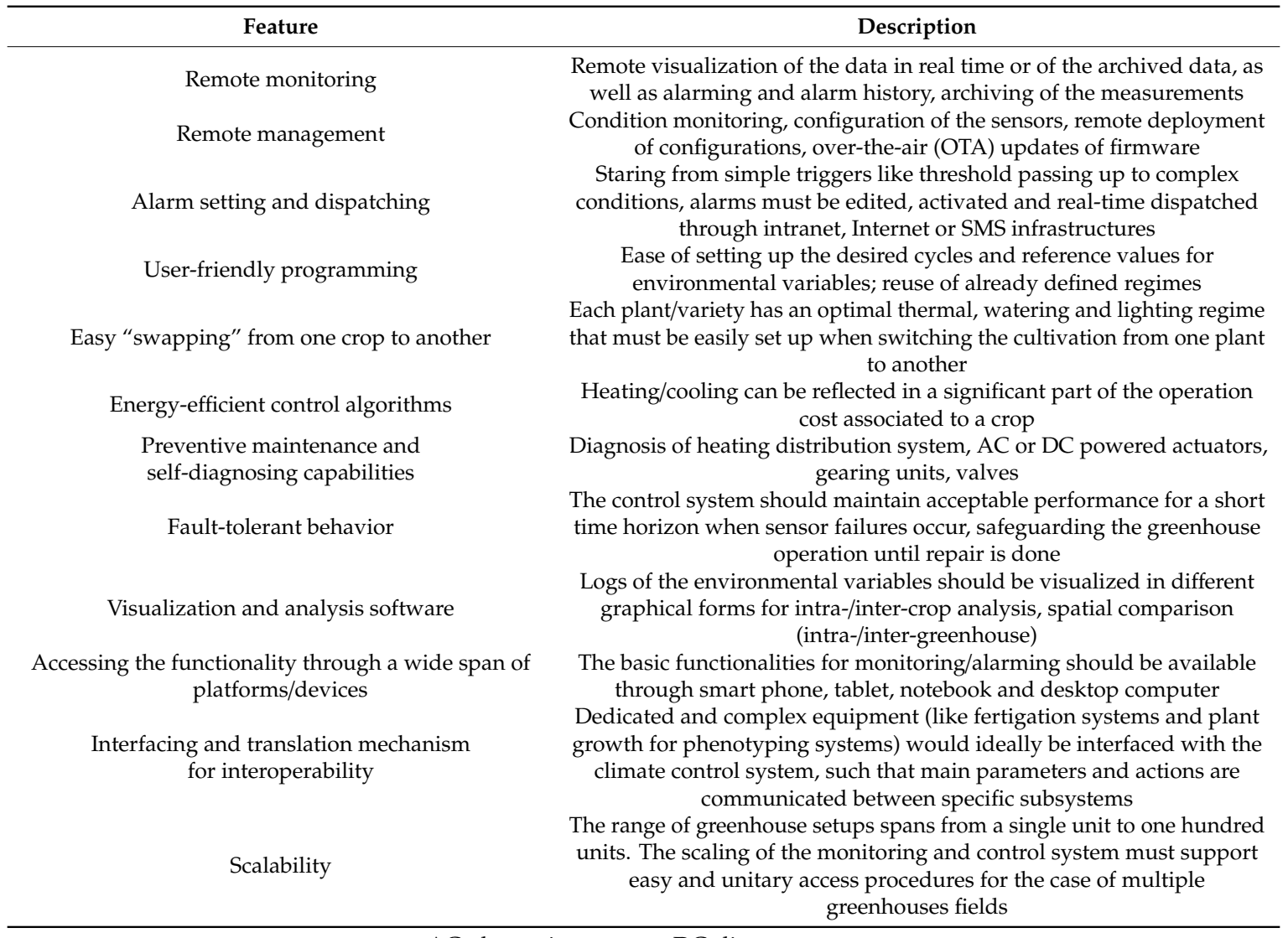

AC-alternating current, DC-direct current

\subsection{Analysis of the Measurands}

In recent decades, greenhouses management systems have undergone a process of deep development, and many types of sensors have been used to record various environmental information [17]. Determining what the basic measurands that have to be considered are is essential for the design of a monitoring and control system for the greenhouse environment. In other words, what are the physical quantities able to characterize the environment and provide valuable information for the automatic control system, whose values will be quantized by the system?

Three environmental variables (indoor temperature, humidity and $\mathrm{CO}_{2}$ concentration) are essential for characterizing the status of the greenhouse environment, representing major factors that influence the level and uniformity of crop growth [17-19]. As demonstrated with several validated models, the values of other variables such as the temperatures of cover, canopy and floor can be reconstructed from this basic set [20].

Beside these, the solar radiation is an environmental factor for characterizing the microclimate in greenhouse models used for managing and predicting the growth process in plants [21].

It is well known that all plants need solar radiation, $\mathrm{CO}_{2}$, water and nutrients to produce biomass through photosynthesis process [22]. Moreover, solar radiation is an important factor contributing to the calculation of water requirements and the assessment of environmental conditions in precision farming applied in protected cultivation areas [23-25].

The main environmental factors affecting greenhouse plants include air and root-zone temperatures and humidity, light conditions, as well as $\mathrm{CO}_{2}$ concentration [26]. Proper management of these parameters leads to maximum productivity yields with minimum energy inputs that have a direct impact on plant growth and development and play a key role in preventing stressors [27]. 
While the inside air parameters are essential factors, not less important are those related to soil. The models for soil temperature prediction as a function of depth rely on estimated soil thermal diffusivities, strongly influenced by the volumetric soil water content [28]. This demonstrates that measuring soil humidity (volumetric soil water content) and soil temperature at least at a single depth level can prove significant insight into soil temperature dynamic.

Evapotranspiration (ET) is the primary process affecting leaf temperature, crop water requirements and the greenhouse microclimate, characterizing the water loss from the soil or substrates and plant surfaces [29]. Stress conditions, especially drought and overheating, are often linked, especially when reducing the intensity of transpiration causes the leaf temperature to rise, with important associated damage to cellular structures, proteins and enzymes [30]. When pad and fan cooling are used, ET processes are strongly influenced, indicating that beside air temperature, air relative humidity, $\mathrm{CO}_{2}$ concentration, solar radiation and soil moisture, one should also consider the wind speed and direction measurements within the canopy boundary layer.

Since the local, internal environmental variables are greatly influenced by the outdoor environmental variables [31], which are seen by the control system as main disturbances, measuring these external variables can offer much insight for modeling, control or prediction procedures. According to [32], the relevant variables are outdoor temperature, outdoor $\mathrm{CO}_{2}$ concentration, outdoor relative humidity, wind speed and diffuse and direct solar radiation.

While all the above-mentioned environmental variables of the greenhouse impact the crop evolution, the most accurate feedback is provided by the plants. For the evaluation of plant growth, measures like stem diameters, sap flow rates [33], expansion of fruit and leaf temperatures have been proposed [34]. Another validated approach is the monitoring of daily weight accumulation processes [35]. The evaluation of the status of health based on chlorophyll fluorescence is also targeted by new sensors [36,37] that also act as detectors of plant stress factors and are able to provide valuable feedback like early warning of possible plant disease outbreaks before production rates are dramatically affected.

\subsection{Spatial Variation}

It is well acknowledged that the spatial distribution of the environmental variables within the greenhouse volume is not homogeneous. The vertical temperature distribution is important and acknowledged by growers. Even in well-designed agricultural buildings, large gradients of environmental parameters exist, and the spatial profiles for the natural ventilation and the use of evaporative cooling are significantly different [38]. In designing the CEA control equipment, the existence of spatial distributions is a factor to account for [32].

These considerations lead to some question of considerable practical interest:

- If one needs to deploy an array of sensors in order to observe details of the distribution and its dynamics, how large should this array be?

- What are the relevant positions in relation to greenhouse geometry and growing setups?

- How should a spatial averaging strategy able to provide the temperature, humidity or $\mathrm{CO}_{2}$ content values in the closed-loop control system be implemented?

To answer to the first question the grower must understand how important the characterization of the plant microclimate for a specific crop is.

The local measurement at the plant level in the vicinity of the leaves or fruits might be desirable, but its implementation is not trivial: cabled sensor configurations might be hard to install and maintain, favoring the adoption of wireless, battery/solar-powered sensors.

\subsection{Common Categories of Actuators}

The larger part of the actuators encountered in the greenhouse are the on/off type, but there are cases when a continuous control signal (voltage or current) must be used for proportional 
valves, variable frequency drivers, voltage-controlled pulse-width modulation (PWM) drivers, rotary positioners, etc. The most common actuators are enumerated as follows:

- Actuators associated with the ventilation (roof-windows, side-windows and fans).

- Actuators associated with the heating (valves and pumps).

- Actuators associated with the curtains (shading screens and energy screens).

- Actuators associated with lighting equipment (dimmers for high voltage sodium lamps and light-emitting diode (LED) lamps).

- Actuators associated with irrigation (valves and pumps).

- Complex fertigation stations.

\subsection{Energy-Efficient Control}

Since the environmental features of the cultivation areas impact the costs associated with heating/cooling, they strongly affect the sustainability of the production [39]. Beside these costs, one should carefully consider the costs of using supplemental lighting in winter. The control strategies aiming at improving the efficiency of energy usage should address several topics:

- Adaptability of the prescribed microclimate regimes to the specifics of the crop (optimized temperature range).

- Optimal use of resources, like harmonizing optimal temperature with the light availability [39].

- Use of appropriate control algorithms and actuator modulating methods such that overshoots are avoided.

- Use of short-term weather forecasting information for implementing heat-storing/heat-releasing techniques that would save heating/cooling energy.

\subsection{Cost of the Operation}

Achieving a level of sustainable productivity in greenhouses requires the integration of information and management strategies, as well as a good understanding of the influence exerted by microclimatic parameters. Thus, the correct understanding of variations in environmental conditions in the greenhouse associated with plant requirements at different stages of growth and development deserves special attention [27].

When farmers build a greenhouse and install all the hardware needed for an appropriate operation of the greenhouse, the costs are associated with an initial investment. Beside these, when one looks at the monthly cost associated with the operation of the greenhouse, the heating/cooling costs and the labor costs seem to be the most important. According to Cola et al. [39], in Dutch environmental conditions with advanced and technologically equipped greenhouses, the labor represents almost $50 \%$ of production costs, while for the low-technology greenhouses, the labor costs significantly increase; therefore, it is important to reduce other costs such as heating requirements. At the same time, one must observe that the costs associated with lighting are significant, especially in the winter time and in the most northerly areas, and act as a main driver toward adoption of low-power LED luminaries.

The operation of the remote monitoring/control features also imply subscription costs for data transfer over the Internet, but the relative impact of these is small.

\subsection{Control Methods}

A greenhouse can be modeled as a complex multi-input and multi-output (MIMO) system that is highly nonlinear and strongly coupled, influenced by the outside weather [31]. The basic set of variables that characterize the internal climate are the air temperature and the air humidity. Identifying them as process outputs, [31] considers the schematic representation of the greenhouse shown in Figure 1. 


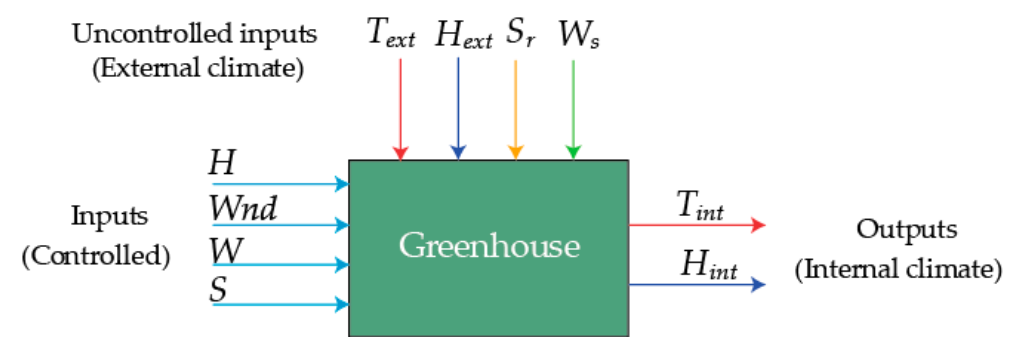

Figure 1. Schematic representation of a greenhouse $\left(T_{\text {ext }}\right.$, external temperature; $H_{\text {ext }}$, external humidity; $S_{r}$, solar radiation; $W_{S}$, wind speed; $H$, heating; $W n d$, window opening state; $W$, watering; $S$, shading; $T_{\text {int }}$, internal temperature; $H_{\text {int }}$, internal humidity) based on [31].

The design of the control system for greenhouses has been extensively addressed in literature extensively in the last years with the attribute "optimal" used more or less motivated. There are several facts which can be emphasized when looking at the evolution of the proposed solutions:

- The design of an optimal controller should obviously start with the definition of the performance indicator(s), where tracking of prescribed temperature, humidity and light profiles, crop production maximization, heating/cooling, energy saving and water saving are usual goals.

- There are complex models for greenhouse climate (lumped parameter or distributed parameter approaches) that have been validated through simulation and comparison with recorded time series.

- A large variety of control methods have been investigated, encompassing simple on/off, proportional integral (PI), proportional integral derivative (PID), adaptive, feed-forward, fuzzy, neuro-fuzzy [40-46] and optimal control solutions [32,47].

The implementation of advanced control strategies became viable only in recent years when the computation power of affordable processors became sufficient for having the possibility to run the associated complex algorithms on embedded devices. Still, the results demonstrated on dedicated simulation environments, backed by complex numerical method libraries, are hardly reproduced on existing commercially available control systems realized in the industry standard approach, based on PLCs.

The complexity of the algorithms associated with the advanced control strategies is the main bottleneck limiting faster adoption and incorporation in a greenhouse ACS:

- The vast majority of processes which occur in greenhouse operation are distributed parameter ones. The algorithms which can be applied for the control of these types of processes require the numerical solving of partial differential equations $[48,49]$, an aspect which introduces consistent programming difficulties for implementation on low-cost embedded processors. However, linearizing and decoupling techniques can help in circumventing such issues, as in the case of the control algorithm based on feedback/feedforward linearization and outer loop controllers demonstrated in [50].

- The internal model control (IMC) strategy is based on using the reference model [41] of the processes from the greenhouse structure, processes which are, in general, strong nonlinear ones. Depending by the nonlinearity type, the software implementation of strong nonlinear models on process computers requires the approximation of special functions, which leads to increased computation time on low-cost 8-bit microcontrollers without integrated floating point support.

- The algorithms associated with the adaptive [40,43], optimal [51-54] and robust [55] control strategies require matrix processing techniques that imply increased computational complexity and the use of special libraries and powerful processors.

- The algorithms associated with the fractional-order control [56] require the implementation of filters with complex structure which in turn require better hardware resources. 
- The online training and identification algorithms of intelligent controllers (neural controllers [31, $44,45,57$ ], neuro-fuzzy controllers [58] and fuzzy controllers [59]) present a high level of complexity, implying difficulties when such an implementation is adopted in agricultural practice.

There is a lag and a reluctance in immediate adoption of the "theoretical" solutions for use in practical control equipment for greenhouses, motivated mainly by the following barriers:

- Simplicity is often associated with reliability, and users prefer the reuse of practice-validated approaches, based on equipment with which they are already accustomed.

- The design, development, testing and certification cycles for measurement and control devices dictate a return-on-investment approach such that the producers do not hurry to incorporate latest algorithms.

- The complexity of some control algorithms requires powerful machines (computers) that are not affordable for many farmers and that are even more expensive if designed for operation in harsh environments.

Another interesting research direction is to target the possible use of PID-type controllers with on/off actuators in order to minimize the system energy losses.

\subsection{Control Architectures}

The key towards understanding a modern ACS with the aim of implementing CEA for greenhouses is the hierarchical approach of the ACS. As indicated in [32], there are two basic levels: an operational level that performs the actual control and a strategic level that serves as a supervisor, whose task is to translate the grower information on the tactical level into information that can be used on the operational level.

As explained in [32], there are two approaches. In the classic one (Figure 2), the grower interacts with the greenhouse climate computer via settings, such as those for upper and lower thresholds of day and night temperatures, upper thresholds on relative humidity, window opening enhancement at high radiation; there can easily be several hundred settings. In the advanced one (Figure 3), optimal greenhouse climate management is automated through a crop growth controller.

In relation to Figure 2, this can be rephrased as follows:

- A collection of sensor and controller devices can implement the operational level, i.e., the necessary closed-loop control actions to bring the environmental variables at the prescribed reference values.

- The strategic level can be further divided into a crop planning module (CPM) and an interfacing block (IB), as shown in Figure 3, so the interaction of the grower is done through the CPM in the classic approach and the growth controller passes the "supervisory" information to the operational level through a standardized format accepted by IB in the advanced approach.

Since the large majority of the growing facilities use the classic approach, one can observe that the ease of use of the CPM will mostly impact the user experience, acting as the main instrument through which the grower can "steer" the crop growth. On the other hand, a seamless transfer of the high-level prescription towards the operational level depends on the "translation" mechanism offered by the IB, important in both classical and advanced setups (Figure 4). 


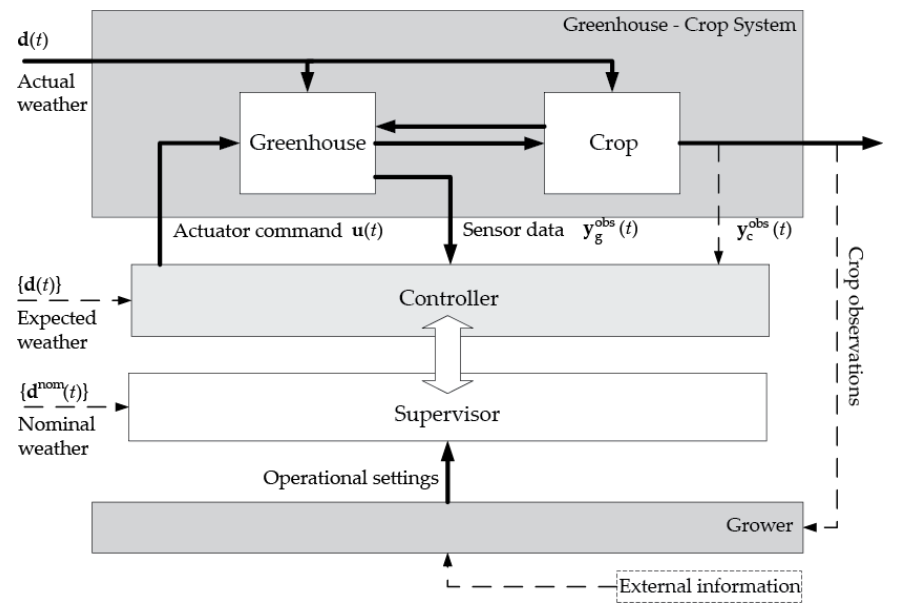

Figure 2. Hierarchical framework for greenhouse cultivation control [32].

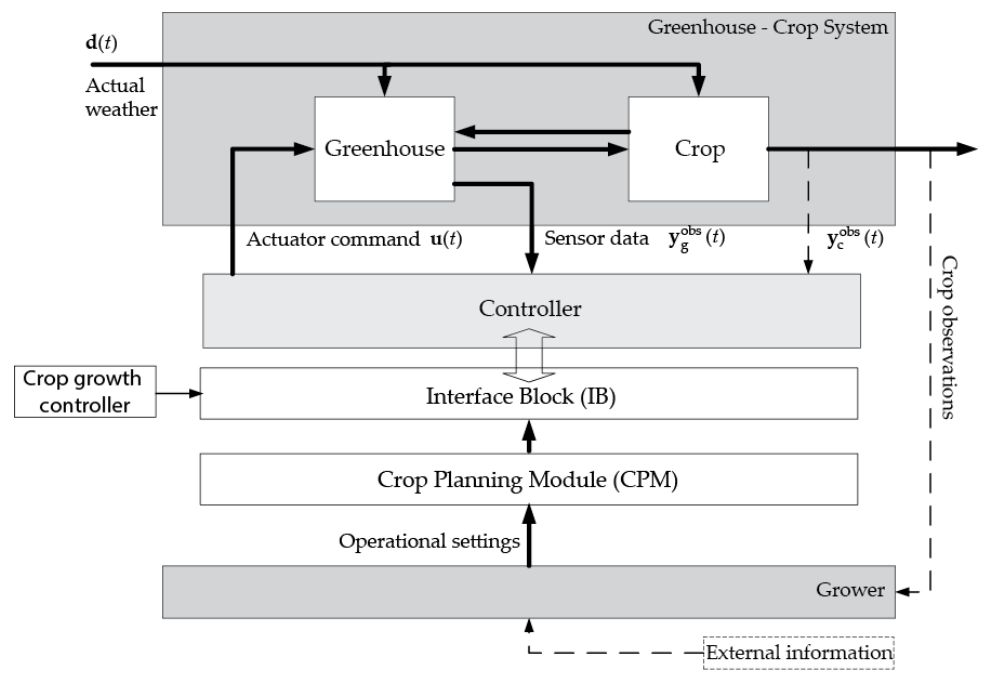

Figure 3. Crop planning module (CPM) and an interfacing block (IB) (adapted from [32]).

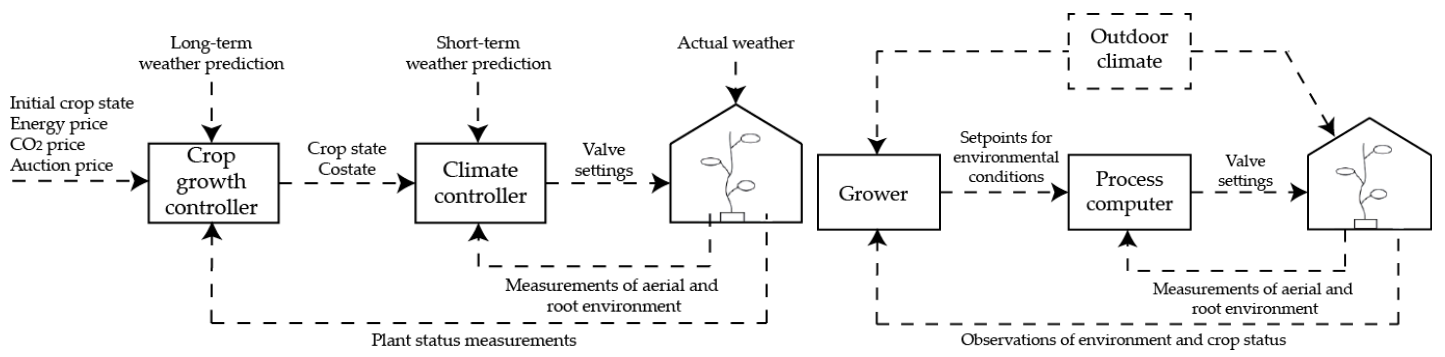

Figure 4. Optimal greenhouse climate management and "classical" climate control procedure in current horticultural practice [32].

The approach toward the proposed implementation of the CPM and IB can be described as follows:

- A software application enables the specification of daily profiles (24 h) for each controlled environmental variable by allowing the grower to declare a sequence of time intervals and associate a reference value to each interval.

- For each environmental variable, the information introduced by the grower is encoded into a process containing a sequence of phases. The prescribed environment for a crop will be encoded as a set of processes. 
- The set of processes has two temporal attributes, namely the starting date and the duration (in days), such that the whole growing period for each crop can be divided into several stages with each having its associated set of processes.

- Two mechanisms are implemented for IB, with the first being the publication of a set of processes in a hierarchical description format (set $>$ process $>$ phase) which are encoded into low-memory-footprint binary representations and the second being the distribution of the compacted representation toward the targeted control module via the system gateway.

\subsection{Topologies and Network Architectures for Distributed Control Networks}

Three basic aspects are of primary importance when designing a communication architecture for a distributed control system application:

a. The network topology, which specifies the way in which the smart nodes (sensors, actuators and data concentrators) are connected to each other.

b. The failure-handling capabilities, in the sense of preventing the loss of power or the interruption of the transmission medium for several nodes from being able to interrupt/block the communication in the control network and/or significantly degrade the control performance.

c. The constraints imposed on cabling and interfacing costs are translated into communication constraints (limited bandwidth, time delays and packet dropouts) that are known to limit the performance of a distributed control system.

Beside these aspects, adherence to standard protocol and transmission standards would assure interoperability and support for debugging. The basic network topologies encountered in industry are ring (where each node is connected to the two neighboring nodes), star (where each node is connected to a central node), bus (where all nodes are connected to a shared backbone medium) and tree (a hierarchical multilevel setup, with root node, interior nodes, and leaf nodes).

For the addressed ACS, the proposed organization of the network is the multidrop bus topology (Figure 5). The access to the multidrop serial bus is regulated by a token-passing procedure (typically associated with the message passing toward a neighbor node in the ring topology). Such a mechanism can regulate the activity periods of the controller nodes and master-slave pooling procedure that govern the message exchange between a controller and its associated sensor and actuator nodes.

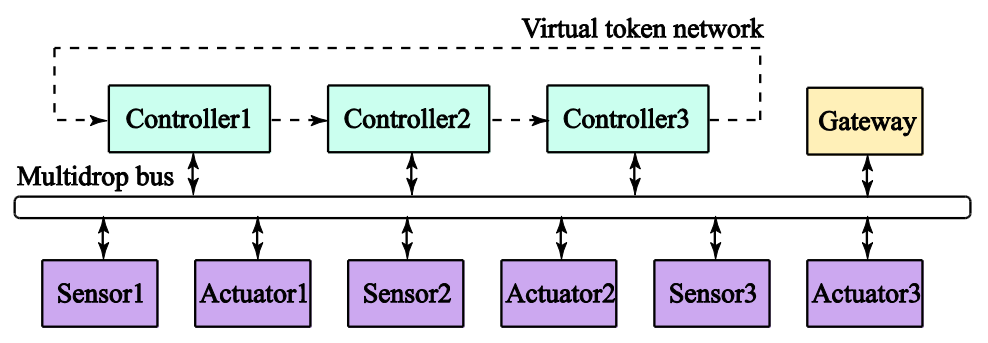

Figure 5. Typical wired configuration [15].

Whenever a controller node receives the permission to access the bus, it may initiate the execution of a message cycle where the master sends/requests frames to/from the associated sensors and actuators. The aspects mentioned in point $b$ of the list above are addressed by the introduction of an inactivity timeout, in the sense of enabling a controller node to initiate a communication cycle when a defective neighbor node does not transfer the bus-granting message. When a gateway is present, before sending the bus granting message to the next controller, the current controller interrogates the gateway about its need to use the bus; the bus-granting message is sent to the next controller only when the gateway signals the fact it does not need the bus.

For an ACS targeting greenhouse environment control, the constraints mentioned in point c of the list above should be considered from a double perspective. On one hand, the typically slow 
processes allow for sampling intervals ranging from seconds to minutes, allowing low transmission rates (and implicitly large bus cabling segment capacities/lengths). On the other hand, the impact of the number of controller nodes on the real sampling rate attainable by a controller in the virtual token network would favor the usage of short messages (payloads with reduced byte number).

\subsection{Energy-Efficient Control}

In order to examine the means of achieving better energy efficiency in simple setups with on/off actuators, "hybrid" controllers (a cascade of bi-positional (on/off) and PID controllers) might be considered. In fact, it is interesting to see if this kind of period-modulated actuation might provide a PWM-like performance for the case of controlling the temperature in a greenhouse. The used control structure is presented in Figure 6.

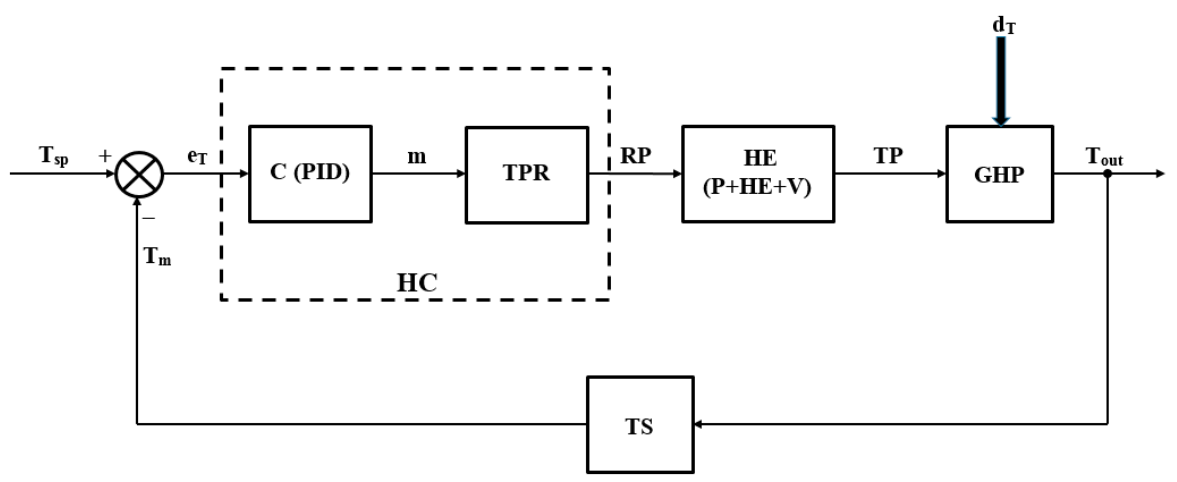

Figure 6. Control structure for the air temperature control inside the greenhouse (GHP, greenhouse heating process; $\mathrm{HE}$, heating element; $\mathrm{P}$, pump; V, ventilator; $\mathrm{TS}$, temperature sensor; $\mathrm{HC}$, hybrid controller; C (PID), PID-type controller; TPR, bi-positional (on/off) controller; $\mathrm{T}_{\mathrm{sp}}$, temperature setpoint signal; $\mathrm{T}_{\mathrm{m}}$, feedback signal (measured temperature); $\mathrm{e}_{\mathrm{T}}$, temperature error signal; $\mathrm{m}$, modulation index; $\mathrm{RP}$, rectangle pulse (control signal); $\mathrm{TP}$, thermal power; $\mathrm{T}_{\text {out }}$, output temperature (controlled signal, air temperature inside the greenhouse); $\mathrm{d}_{\mathrm{T}}$, equivalent disturbance signal that directly modifies the $\mathrm{T}_{\text {out }}$ value (e.g., the external temperature or solar radiation)).

All the signals from the control structure are functions that depend on the independent variable time (t). The greenhouse heating process (GHP) has a second-order structure. The heating element (HE) is a third-order proportional element, and the temperature sensor (TS) is a first-order proportional element. The ideal structure of the PID controller is given by

$$
m(t)=K_{C} \cdot e_{T}(t)+\frac{K_{C}}{T_{I}} \cdot \int e_{T}(t) d t+K_{C} \cdot T_{D} \cdot \frac{d e_{T}(t)}{d t}
$$

where $K_{C}$ is the controller proportionality constant, $T_{I}$ is the controller integral time constant and $T_{D}$ is the controller derivative time constant. In practical implementations, the ideal form of the controller has to be augmented with a first-order filter, having the time constant denoted with $T_{f}$.

In relation to the $\mathrm{m}(\mathrm{t})$ value $(0 \leq \mathrm{m}(\mathrm{t}) \leq 1)$, the output signal from the bi-positional (on/off) controller (TPR) can have two possible logical values: the "0" value, which implies the stop of the HE, and the " 1 " value, which implies the operation of the $\mathrm{HE}$ at maximum power. Considering the period of the rectangle pulse (RP) signal, equal to $T_{R P}, T_{1}=m(t) \cdot T_{R P}$ represents the duration from each period in which the RP signal takes the value " 1 " and $T_{2}=(1-\mathrm{m}(\mathrm{t})) \cdot \mathrm{T}_{\mathrm{RP}}$ represents the duration from each period in which the RP signal takes the value " 0 ".

\subsection{Comparative Study of Reported Implementations for Greenhouse Control Systems}

An extensive comparison, based on 28 features, is presented in Table 2 (Physis-based solutions vs. commercially available solutions), and Table 3 (Physis-based solutions vs. systems presented 
in literature). Some features are a clear indication of the industrial maturity level of the proposed solution: appropriate sealing, bus length appropriate for production greenhouses, remote configuration for sensors/controllers, inputs for external sensors (from other producers), preventive maintenance and self-diagnosing capabilities and scalability for a large number of greenhouses. The Physis-based solution shares all these with some of the commercial systems. Other features rather prove the suitability of approaches based on recent technological/methodological advances: low-power hardware, sensors based on pre-calibrated digital output transducers (with guaranteed error margins), Ethernet gateway with an embedded web server, OTA updates of firmware, integrated upper-level control or upper-level-control ready and fault-tolerant behavior. This second category is well covered by the solution proposed in this paper, with features being shared with only a few other systems. Among the distinctive features of the proposed solution are the following: sensors with local display of measurand values, remote configuration of the controllers, user-friendly editing of complex alarm conditions, easy "swapping" from one crop to another (reuse of predefined regimes), preventive maintenance and self-diagnosing capabilities and structured approach for scalability in the case of installations with a large number of greenhouse compartments. 
Table 2. Comparative study between the Physis platform and commercially available systems.

\begin{tabular}{|c|c|c|c|c|c|c|c|}
\hline Feature & Physis & $\begin{array}{l}\text { SPAGNOL's Greenhouse } \\
\text { Automation Solution [1] }\end{array}$ & $\begin{array}{l}\text { Micro Grow's Growcom } \\
\text { Controller [2] }\end{array}$ & $\begin{array}{l}\text { Autogrow's MultiGrow } \\
\text { Controller [4] }\end{array}$ & $\begin{array}{c}\text { Sensaphone's } \\
\text { Greenhouse Remote } \\
\text { Monitoring Systems [6] }\end{array}$ & $\begin{array}{l}\text { Monnit Remote Monitoring } \\
\text { Systems for Greenhouse } \\
\text { Monitoring [7] }\end{array}$ & $\begin{array}{c}\text { Denso's Climate Control } \\
\text { System for Greenhouse [11] }\end{array}$ \\
\hline Low-cost hardware & Yes & $\mathrm{N} / \mathrm{A}^{1}$ & $\mathrm{~N} / \mathrm{A}$ & $\mathrm{N} / \mathrm{A}$ & N/A & $\begin{array}{c}\text { Yes, wireless sensors start at } \\
\$ 49 \text {, a simple setup (sensors, } \\
\text { gateways, software) for less } \\
\text { than } \$ 500\end{array}$ & $\begin{array}{c}\text { No, suggested retail price (as } \\
\text { of January } 2020): \\
¥ 3,700,000 / 44,250,000 \text { for } \\
\text { single/double greenhouse } \\
\text { control unit }\end{array}$ \\
\hline Low-power hardware & Yes & $\mathrm{N} / \mathrm{A}$ & N/A & $\mathrm{N} / \mathrm{A}$ & $\mathrm{N} / \mathrm{A}$ & Yes, for wireless sensors & $\mathrm{N} / \mathrm{A}$ \\
\hline $\begin{array}{l}\text { Appropriate sealing for } \\
\text { devices and connectors, } \\
\text { ruggedized device case }\end{array}$ & $\begin{array}{l}\text { All devices sealed to } \\
\text { IP68, UV-and } \\
\text { corrosion-resistant cases } \\
\text { and connectors }\end{array}$ & $\begin{array}{l}\text { Ingress protection for sensors: } \\
\text { IP53; Protection degree for } \\
\text { controllers: IP55 }\end{array}$ & $\begin{array}{l}\text { Enclosure weatherproof, } \\
\text { clear cover, lockable }\end{array}$ & $\mathrm{N} / \mathrm{A}$ & $\begin{array}{c}\text { NEMA-4X } \\
\text { weatherproof enclosure }\end{array}$ & $\begin{array}{l}\text { Enclosure Rating: NEMA } 1,2 \\
4,4 \times, 12 \text { and } 13 \text { rated, sealed } \\
\text { and weather-proof }\end{array}$ & $\mathrm{N} / \mathrm{A}$ \\
\hline Bus topology & Multidrop & $\begin{array}{l}\text { Star (multiple sensors } \\
\text { connected to one controller) }\end{array}$ & $\mathrm{N} / \mathrm{A}$ & Daisy chain & N/A & $\begin{array}{c}\text { Star network (multiple } \\
\text { wireless sensors connected to } \\
\text { a hub) }\end{array}$ & $\mathrm{N} / \mathrm{A}$ \\
\hline Bus standard & Modbus RS-485 & S-BUS interface & $\mathrm{N} / \mathrm{A}$ & RS-485 & $\mathrm{N} / \mathrm{A}$ & $\begin{array}{l}\text { Monnit proprietary radio } \\
\text { protocol }\end{array}$ & $\mathrm{N} / \mathrm{A}$ \\
\hline $\begin{array}{l}\text { Bus length (sensors to } \\
\text { control unit) }\end{array}$ & Up to $1.6 \mathrm{~km}$ & Up to $500 \mathrm{~m}$ & N/A & Up to $1.6 \mathrm{~km}$ & N/A & Wireless range: $1000+$ feet & N/A \\
\hline $\begin{array}{l}\text { Digital output for on/off } \\
\text { actuation }\end{array}$ & $\begin{array}{l}\text { Yes, 5-output and } \\
\text { 8-output devices }\end{array}$ & $\begin{array}{l}\text { Yes, } 8 \text { relay outputs and } 2 \text { free } \\
\text { slots for expansion boards for } \\
\text { the climate controller C-Fenix, } \\
\text { free slots for expansion boards } \\
\text { available for Process } C 5 / \mathrm{C} 6 \\
\text { global controller }\end{array}$ & $\begin{array}{l}\text { Yes, } 12 \text { universal outputs for } \\
\text { connection to separate } \\
\text { control boxes }\end{array}$ & $\begin{array}{l}\text { Yes, } 10 \text { relays that may } \\
\text { be connected to } \\
\text { paired/single output } \\
\text { modules }\end{array}$ & $\begin{array}{l}\text { Yes, one relay output for } \\
\text { automatic or manual } \\
\text { control of external } \\
\text { devices }\end{array}$ & $\begin{array}{l}\text { Yes, 2-output wireless control } \\
\text { devices }\end{array}$ & $\begin{array}{l}\text { Yes, outputs for control of } \\
\text { greenhouse equipment (top } \\
\text { ventilator, curtains, window, } \\
\text { circulation fans) and air } \\
\text { conditioning equipment (heat } \\
\text { pump, } \mathrm{CO}_{2} \text { generator, heating } \\
\text { unit, fogging system) } \\
\end{array}$ \\
\hline Voltage/current outputs & $\begin{array}{c}\text { 2-output smart } \\
\text { actuators (0-10 V or 0-5 } \\
\text { V configurable) }\end{array}$ & $\begin{array}{l}\text { Expansion boards may include } \\
0-10 \mathrm{~V} \text { analogic outputs }\end{array}$ & N/A & N/A & N/A & N/A & N/A \\
\hline $\begin{array}{l}\text { Pulse-Width Modulated } \\
\text { (PWM) outputs }\end{array}$ & $\begin{array}{l}\text { 1-output smart actuator } \\
\text { with optically isolated } \\
\text { output }\end{array}$ & N/A & $\begin{array}{c}\text { Some outputs, like fogging, } \\
\text { may be commanded in } \\
\text { pulse mode based on the } \\
\text { run and wait time set by the } \\
\text { user }\end{array}$ & N/A & N/A & N/A & N/A \\
\hline On/off controllers & $\begin{array}{c}\text { Yes, } 5 \text { or } 8 \text { relay outputs } \\
\text { (programmable } \\
\text { reference and hysteresis } \\
\text { values) }\end{array}$ & $\mathrm{N} / \mathrm{A}$ & $\begin{array}{l}\text { Yes, control outputs with } \\
\text { configurable parameters }\end{array}$ & $\mathrm{N} / \mathrm{A}$ & $\mathrm{N} / \mathrm{A}$ & $\begin{array}{c}\text { Yes, } 2 \text { relay outputs } \\
\text { (configurable user-defined } \\
\text { thresholds) }\end{array}$ & $\mathrm{N} / \mathrm{A}$ \\
\hline $\begin{array}{l}\text { Proportional Integral } \\
\text { (Derivative)-PI (D) } \\
\text { controllers }\end{array}$ & $\begin{array}{c}\text { Implemented as discrete } \\
\text { controllers (works in } \\
\text { conjunction with } \\
\text { PWM/voltage output } \\
\text { actuators) }\end{array}$ & $\mathrm{N} / \mathrm{A}$ & N/A & N/A & N/A & N/A & N/A \\
\hline
\end{tabular}


Table 2. Cont

\begin{tabular}{|c|c|c|c|c|c|c|c|}
\hline Feature & Physis & $\begin{array}{l}\text { SPAGNOL's Greenhouse } \\
\text { Automation Solution [1] }\end{array}$ & $\begin{array}{l}\text { Micro Grow's Growcom } \\
\text { Controller [2] }\end{array}$ & $\begin{array}{l}\text { Autogrow's MultiGrow } \\
\text { Controller [4] }\end{array}$ & $\begin{array}{c}\text { Sensaphone's } \\
\text { Greenhouse Remote } \\
\text { Monitoring Systems [6] }\end{array}$ & $\begin{array}{c}\text { Monnit Remote Monitoring } \\
\text { Systems for Greenhouse } \\
\text { Monitoring [7] }\end{array}$ & $\begin{array}{l}\text { Denso's Climate Control } \\
\text { System for Greenhouse [11] }\end{array}$ \\
\hline $\begin{array}{l}\text { Voltage/current inputs for } \\
\text { external sensors }\end{array}$ & $\begin{array}{l}\text { Voltage/current/resistance } \\
\text { configurable input, } \mathrm{A} / \mathrm{D} \\
\text { conversion resolution of } \\
16 / 24 \text { bits }\end{array}$ & N/A & 8 sensor input terminals & $\begin{array}{l}\text { Yes, e.g., Electrical } \\
\text { Conductivity (EC) } \\
\text { probe, } \mathrm{pH} \text { probe }\end{array}$ & $\begin{array}{c}\text { Up to } 8 \text { (Sensaphone } \\
1400 \& 1800 \text { Monitoring } \\
\text { Systems) or } 12 \\
\text { (Sensaphone Sentinel) } \\
\text { different inputs } \\
\text { including } 2.8 \mathrm{~K} \text { and } 10 \mathrm{~K} \\
\text { temperature sensors, } \\
\text { and } 4-20 \mathrm{~mA} \text { current } \\
\text { sources }\end{array}$ & $\begin{array}{l}\text { Voltage/current/resistance } \\
\text { input }\end{array}$ & N/A \\
\hline $\begin{array}{l}\text { Sensor with local display of } \\
\text { measurand values }\end{array}$ & $\begin{array}{l}\text { Yes, sensor devices with } \\
\text { LCD resolution } 400 \times \\
240\end{array}$ & N/A & N/A & $\mathrm{N} / \mathrm{A}$ & N/A & N/A & $\mathrm{N} / \mathrm{A}$ \\
\hline $\begin{array}{l}\text { Sensor with precalibrated } \\
\text { digital output transducers }\end{array}$ & $\begin{array}{c}\text { Yes, temperature, } \\
\text { humidity, pressure, } \mathrm{CO}_{2} \\
\text { level }\end{array}$ & N/A & $\mathrm{N} / \mathrm{A}$ & $\mathrm{N} / \mathrm{A}$ & $\mathrm{N} / \mathrm{A}$ & Yes & $\mathrm{N} / \mathrm{A}$ \\
\hline Remote monitoring & $\begin{array}{c}\text { Yes, Ethernet gateway } \\
\text { with embedded server } \\
\text { and TCP/IP connection } \\
\text { to dedicated computer } \\
\text { software }\end{array}$ & $\begin{array}{l}\text { Yes, controllers may be } \\
\text { connected to Ethernet or a } \\
\text { mobile modem accessory may } \\
\text { be used for monitoring through } \\
\text { a web portal or through } \\
\text { dedicated software }\end{array}$ & $\begin{array}{l}\text { Yes, controllers may be } \\
\text { connected on the RS- } 485 \\
\text { bus to a Growlink Module } \\
\text { based on a Micro PC } \\
\text { running dedicated } \\
\text { Windows software. Remote } \\
\text { connection to the Growlink } \\
\text { Module facilitates } \\
\text { monitoring of the system } \\
\text { parameters. }\end{array}$ & Yes, via a web portal & Yes, via web browser & $\begin{array}{l}\text { Yes, via web browser, } \\
\text { iPhone/Android app or } \\
\text { self-hosted enterprise } \\
\text { software }\end{array}$ & Yes, via web browser \\
\hline $\begin{array}{l}\text { Remote configuration of the } \\
\text { sensors }\end{array}$ & $\begin{array}{l}\text { Offset, gain, averaging } \\
\text { and median filter } \\
\text { lengths are configurable } \\
\text { for each measurand }\end{array}$ & N/A & N/A & N/A & $\begin{array}{l}\text { Allows calibration of } \\
\text { temperature sensors. }\end{array}$ & $\begin{array}{l}\text { Allows access to calibrate } \\
\text { certain types of sensors, } \\
\text { editing of advanced sensor } \\
\text { configurations }\end{array}$ & $\mathrm{N} / \mathrm{A}$ \\
\hline $\begin{array}{l}\text { Remote configuration of the } \\
\text { controllers }\end{array}$ & $\begin{array}{l}\text { Sensor to input channel } \\
\text { and output channel to } \\
\text { smart actuator } \\
\text { mappings configurable. } \\
\text { Hourly reference values } \\
\text { and interpolation } \\
\text { configurable. Active set } \\
\text { of processes } \\
\text { configurable. }\end{array}$ & $\begin{array}{l}\text { Configurable parameters for } \\
\text { control of up to } 4 / 10 / 40 \text { zones } \\
\text { (up to max } 6 \text { daily periods) }\end{array}$ & $\begin{array}{l}\text { Configurable parameters for } \\
\text { up to } 4 \text { separate daily } \\
\text { operation modes including } \\
\text { differential (day, midday, } \\
\text { evening, night) }\end{array}$ & $\mathrm{N} / \mathrm{A}$ & $\begin{array}{l}\text { Call-in type interface to } \\
\text { check status and make } \\
\text { programming changes }\end{array}$ & $\begin{array}{l}\text { Configurable thresholds for } \\
\text { on/off actuation }\end{array}$ & $\begin{array}{l}\text { Climate control settings using } \\
\text { exclusively developed PC }\end{array}$ \\
\hline $\begin{array}{l}\text { Over-the-air (OTA) updates } \\
\text { of firmware }\end{array}$ & $\begin{array}{l}\text { Available for gateway- } \\
\text { and } \\
\text { 32-bit-processor-based } \\
\text { sensors }\end{array}$ & $\mathrm{N} / \mathrm{A}$ & N/A & $\mathrm{N} / \mathrm{A}$ & N/A & $\begin{array}{l}\text { Available for one of the } 2 \\
\text { microprocessors of the } \\
\text { Ethernet gateway (the one } \\
\text { that does not handle the } \\
\text { interactions with the sensors) }\end{array}$ & N/A \\
\hline
\end{tabular}


Table 2. Cont.

\begin{tabular}{|c|c|c|c|c|c|c|c|}
\hline Feature & Physis & $\begin{array}{l}\text { SPAGNOL's Greenhouse } \\
\text { Automation Solution [1] }\end{array}$ & $\begin{array}{l}\text { Micro Grow's Growcom } \\
\text { Controller [2] }\end{array}$ & $\begin{array}{l}\text { Autogrow's MultiGrow } \\
\text { Controller [4] }\end{array}$ & $\begin{array}{c}\text { Sensaphone's } \\
\text { Greenhouse Remote } \\
\text { Monitoring Systems [6] }\end{array}$ & $\begin{array}{c}\text { Monnit Remote Monitoring } \\
\text { Systems for Greenhouse } \\
\text { Monitoring [7] }\end{array}$ & $\begin{array}{l}\text { Denso's Climate Control } \\
\text { System for Greenhouse [11] }\end{array}$ \\
\hline $\begin{array}{l}\text { Simple alarming (threshold } \\
\text { triggers) }\end{array}$ & $\begin{array}{l}\text { Alerts through web } \\
\text { browser, TCP/IP } \\
\text { connection to dedicated } \\
\text { software, e-mails }\end{array}$ & $\begin{array}{l}\text { Alerts in case of alarms or } \\
\text { anomalies through the mobile } \\
\text { modem accessory (SMS/calls) }\end{array}$ & $\begin{array}{l}\text { E-mail/text alerts when } \\
\text { using the Growlink Module; } \\
\text { power failure and sensor } \\
\text { alarm output contacts }\end{array}$ & $\begin{array}{l}\text { Alerts via rule-based } \\
\text { systems for alarm } \\
\text { conditions by e-mail } \\
\text { and text message }\end{array}$ & $\begin{array}{l}\text { Instant alerts by voice } \\
\text { phone calls, e-mail or } \\
\text { text on conditions going } \\
\text { outside preset ranges. } \\
\text { Local alarming for } \\
\text { on-site personnel. }\end{array}$ & $\begin{array}{l}\text { Alert based on sensor reading } \\
\text { or activity, battery alert, } \\
\text { device inactivity alert }\end{array}$ & $\begin{array}{l}\text { Alert functions: external } \\
\text { output alert, temperature } \\
\text { alert (high/low), sensor error } \\
\text { detection }\end{array}$ \\
\hline Complex alarm conditions & $\begin{array}{c}\text { Alerts through web } \\
\text { browser, TCP/IP } \\
\text { connection to dedicated } \\
\text { software, e-mails } \\
\end{array}$ & N/A & $\mathrm{N} / \mathrm{A}$ & $\begin{array}{l}\text { Alerts via rule-based } \\
\text { systems for alarm } \\
\text { conditions by e-mail } \\
\text { and text message } \\
\end{array}$ & N/A & N/A & $\mathrm{N} / \mathrm{A}$ \\
\hline $\begin{array}{l}\text { Easy “swapping" from one } \\
\text { crop to another (reuse of } \\
\text { predefined regimes) }\end{array}$ & $\begin{array}{l}\text { Yes, through simple } \\
\text { activation/de-activation } \\
\text { of the predefined sets of } \\
\text { processes }\end{array}$ & $\begin{array}{l}\text { Different control programs may } \\
\text { be activated (e.g., climate zone } \\
\text { to control, vent control, on/off } \\
\text { heating control); programmable } \\
\text { control parameters; } \\
\text { configurable input and output } \\
\text { functions by USB console cable } \\
\text { or Bluetooth console board }\end{array}$ & $\begin{array}{l}\text { Configurable control } \\
\text { parameters and } \\
\text { input/outputs assignments, } \\
\text { activation/deactivation of } \\
\text { control functions }\end{array}$ & N/A & N/A & N/A & $\mathrm{N} / \mathrm{A}$ \\
\hline $\begin{array}{l}\text { Energy-efficient control } \\
\text { algorithms }\end{array}$ & Yes, for heating/cooling & N/A & N/A & N/A & N/A & N/A & $\begin{array}{l}\text { Forecast control for effective } \\
\text { control of windows or } \\
\text { individual machinery } \\
\text { operations }\end{array}$ \\
\hline $\begin{array}{l}\text { Preventive maintenance and } \\
\text { self-diagnosing capabilities }\end{array}$ & $\begin{array}{c}\text { Error detection for } \\
\text { sensor/controller/actuator } \\
\text { nodes and for } \\
\text { electromechanical } \\
\text { actuators }\end{array}$ & $\begin{array}{l}\text { Features like power failure } \\
\text { detection available when using } \\
\text { the power backup accessory }\end{array}$ & $\begin{array}{l}\text { Power failure and sensor } \\
\text { error detection }\end{array}$ & $\mathrm{N} / \mathrm{A}$ & $\begin{array}{l}\text { Power failure } \\
\text { monitoring }\end{array}$ & N/A & Sensor error detection \\
\hline Fault-tolerant behavior & $\begin{array}{l}\text { A smart emulator } \\
\text { module may be } \\
\text { included in the system } \\
\text { for estimating faulty } \\
\text { sensor nodes values }\end{array}$ & N/A & N/A & $\begin{array}{l}\text { Back-up of all settings } \\
\text { and data to secure } \\
\text { servers }\end{array}$ & N/A & N/A & $\begin{array}{l}\text { Fail safe (control at a safe } \\
\text { setting, in the event of sensor } \\
\text { malfunction) }\end{array}$ \\
\hline $\begin{array}{l}\text { Visualization and analysis } \\
\text { software }\end{array}$ & $\begin{array}{c}\text { Yes, visualization and } \\
\text { analysis facilitated by } \\
\text { web browser and } \\
\text { desktop/Android/iOS } \\
\text { app }\end{array}$ & $\begin{array}{l}\text { Yes, supervision and analysis } \\
\text { facilitated by } \\
\text { desktop/Android/iOS app }\end{array}$ & $\begin{array}{l}\text { Yes, graph and report data } \\
\text { available through the } \\
\text { Growlink Module }\end{array}$ & $\begin{array}{l}\text { Yes, through web } \\
\text { browser }\end{array}$ & $\begin{array}{l}\text { Yes, one can monitor } \\
\text { multiple locations, } \\
\text { check specific } \\
\text { equipment status, access } \\
\text { trending reports and } \\
\text { review alarm history } \\
\text { through web browser }\end{array}$ & $\begin{array}{l}\text { Yes, through web browser, } \\
\text { iPhone/Android app }\end{array}$ & $\begin{array}{l}\text { Data history graph display } \\
\text { through web browser }\end{array}$ \\
\hline $\begin{array}{c}\text { Remote } \\
\text { monitoring/alarming } \\
\text { available through smart } \\
\text { phone and tablet }\end{array}$ & Yes & Yes & Yes & Yes & Yes & Yes & Yes \\
\hline
\end{tabular}


Table 2. Cont.

\begin{tabular}{|c|c|c|c|c|c|c|c|}
\hline Feature & Physis & $\begin{array}{l}\text { SPAGNOL's Greenhouse } \\
\text { Automation Solution [1] }\end{array}$ & $\begin{array}{l}\text { Micro Grow's Growcom } \\
\text { Controller [2] }\end{array}$ & $\begin{array}{l}\text { Autogrow's MultiGrow } \\
\text { Controller [4] }\end{array}$ & $\begin{array}{c}\text { Sensaphone's } \\
\text { Greenhouse Remote } \\
\text { Monitoring Systems [6] }\end{array}$ & $\begin{array}{l}\text { Monnit Remote Monitoring } \\
\text { Systems for Greenhouse } \\
\text { Monitoring [7] }\end{array}$ & $\begin{array}{l}\text { Denso's Climate Control } \\
\text { System for Greenhouse [11] }\end{array}$ \\
\hline $\begin{array}{l}\text { Hierarchical, upper-level } \\
\text { optimal control }\end{array}$ & $\begin{array}{l}\text { Not integrated, easily } \\
\text { implementable through } \\
\text { the XML based } \\
\text { description of the set of } \\
\text { processes using the } \\
\text { included interface }\end{array}$ & N/A & N/A & N/A & N/A & N/A & N/A \\
\hline $\begin{array}{l}\text { Scalability (for a large } \\
\text { number of greenhouses) }\end{array}$ & $\begin{array}{l}\text { Multiple nodes may be } \\
\text { connected on a serial } \\
\text { bus into a subnetwork } \\
\text { interfaced by an } \\
\text { embedded gateway } \\
\text { module (up to } 4 \\
\text { greenhouses). Up to } 20 \\
\text { subnetworks are } \\
\text { managed by the } \\
\text { software apps. }\end{array}$ & $\begin{array}{l}\text { Each greenhouse is to be } \\
\text { equipped with its own specific } \\
\text { system (controllers, sensors) } \\
\text { according to the growth needs } \\
\text { of the cultivation. Multiple } \\
\text { controllers can be integrated } \\
\text { into an Ethernet network. }\end{array}$ & $\begin{array}{l}\text { Multiple controllers may be } \\
\text { connected on the serial bus } \\
\text { to a Growlink Module }\end{array}$ & $\begin{array}{l}\text { Up to } 32 \text { modules may } \\
\text { be connected } \\
\text { simultaneously on the } \\
\text { serial bus. Multiple } \\
\text { controllers can be } \\
\text { integrated into an } \\
\text { Ethernet network. }\end{array}$ & $\begin{array}{l}\text { Multiple modules may } \\
\text { be used, but using the } \\
\text { individual access } \\
\text { method }\end{array}$ & $\begin{array}{l}\text { Up to } 100 \text { sensors are } \\
\text { supported by a MonnitLink } \\
\text { wireless gateway. Other } \\
\text { wireless gateways may be } \\
\text { used for expanding the } \\
\text { network. }\end{array}$ & $\begin{array}{l}\text { Single/double greenhouse } \\
\text { control units are available }\end{array}$ \\
\hline
\end{tabular}

${ }^{1}$ N/A-information Not Available/feature Not Applicable.

Table 3. Comparative study between Physis platform and other systems presented in literature.

\begin{tabular}{|c|c|c|c|c|c|c|c|}
\hline Feature & Physis & $\begin{array}{l}\text { SMA Environmental Control } \\
\text { System [60] }\end{array}$ & $\begin{array}{l}\text { FPGA Based Embedded } \\
\text { Control System [61] }\end{array}$ & $\begin{array}{c}\text { Low-Cost Greenhouse } \\
\text { with Open-Source } \\
\text { Control Systems [62] }\end{array}$ & $\begin{array}{c}\text { IoT-Based Greenhouse } \\
\text { Monitoring and } \\
\text { Remote Control } \\
\text { Architecture [63] }\end{array}$ & $\begin{array}{l}\text { MEDRL for Intelligent } \\
\text { Greenhouse Control [64] }\end{array}$ & $\begin{array}{c}\text { Low-Cost Programmable } \\
\text { Controlled Environment [65] }\end{array}$ \\
\hline Low-cost hardware & Yes & $\mathrm{N} / \mathrm{A}^{1}$ & Yes & Yes & No & No & Yes, <1000 EUR \\
\hline Low-power hardware & Yes & N/A & N/A & Yes & N/A & No & Yes \\
\hline $\begin{array}{l}\text { Appropriate sealing for } \\
\text { devices and connectors, } \\
\text { ruggedized device case }\end{array}$ & $\begin{array}{l}\text { All devices sealed to } \\
\text { IP68, UV-and } \\
\text { corrosion-resistant cases } \\
\text { and connectors } \\
\end{array}$ & $\mathrm{N} / \mathrm{A}$ & No & N/A & Yes & No & No \\
\hline Bus topology & Multidrop & N/A & Star & N/A & Star & Star & Star \\
\hline Bus standard & Modbus RS-485 & $\mathrm{N} / \mathrm{A}$ & $\begin{array}{c}\text { Wireless communication } \\
\text { between monitoring unit } \\
\text { (master) and operator unit } \\
\text { (slave) }\end{array}$ & $\begin{array}{l}\text { Serial } / \text { parallel direct } \\
\text { connection to } \\
\text { microcontroller ports }\end{array}$ & Wi Fi/Ethernet & $\begin{array}{l}\text { Serial//2C direct connection to } \\
\text { microcontroller }\end{array}$ & $\begin{array}{l}\text { I2C/1-wire direct connection } \\
\text { to microcontroller }\end{array}$ \\
\hline $\begin{array}{l}\text { Bus length (sensors to } \\
\text { control unit) }\end{array}$ & Up to $1.6 \mathrm{~km}$ & N/A & N/A & Less than $1 \mathrm{~m}$ & $\begin{array}{l}\text { Limited to standard Wi } \\
\text { Fi/Ethernet range }\end{array}$ & Less than $1 \mathrm{~m}$ & Less than $1 \mathrm{~m}$ \\
\hline
\end{tabular}


Table 3. Cont

\begin{tabular}{|c|c|c|c|c|c|c|c|}
\hline Feature & Physis & $\begin{array}{l}\text { SMA Environmental Control } \\
\text { System [60] }\end{array}$ & $\begin{array}{l}\text { FPGA Based Embedded } \\
\text { Control System [61] }\end{array}$ & $\begin{array}{l}\text { Low-Cost Greenhouse } \\
\text { with Open-Source } \\
\text { Control Systems [62] }\end{array}$ & $\begin{array}{l}\text { IoT-Based Greenhouse } \\
\text { Monitoring and } \\
\text { Remote Control } \\
\text { Architecture [63] } \\
\end{array}$ & $\begin{array}{l}\text { MEDRL for Intelligent } \\
\text { Greenhouse Control [64] }\end{array}$ & $\begin{array}{l}\text { Low-Cost Programmable } \\
\text { Controlled Environment [65] }\end{array}$ \\
\hline $\begin{array}{l}\text { Digital output for On/off } \\
\text { actuation }\end{array}$ & $\begin{array}{l}\text { Yes, 5-output and } \\
\text { 8-output devices }\end{array}$ & Yes (6 outputs) & Yes & Yes (3) & Yes (5) & Yes (4) & Yes \\
\hline Voltage/current outputs & $\begin{array}{c}\text { 2-output smart } \\
\text { actuators (0-10 V or 0-5 } \\
\text { V configurable) }\end{array}$ & Yes (4 outputs) & Yes & Yes & Yes & Yes & Yes, LED/TEC driver \\
\hline PWM outputs & $\begin{array}{l}\text { 1-output smart actuator } \\
\text { with optically isolated } \\
\text { output }\end{array}$ & N/A & N/A & $\mathrm{N} / \mathrm{A}$ & N/A & N/A & $\begin{array}{l}\text { Yes, PWM outputs for } \\
\text { controlling the driver of the } \\
\text { thermoelectric cooler module } \\
\text { for heating/cooling, the LED } \\
\text { driver for spectrum } \\
\text { regulation, the circulation } \\
\text { fans }\end{array}$ \\
\hline On/off controllers & $\begin{array}{c}\text { Yes, } 5 \text { or } 8 \text { relay outputs } \\
\text { (programmable } \\
\text { reference and hysteresis } \\
\text { values) }\end{array}$ & Yes & Yes & Yes & Yes & Yes & $\begin{array}{l}\text { Yes, relay outputs for } \\
\text { controlling the humidifier, the } \\
\text { liquid and gas circulation } \\
\text { pumps, the LED panel }\end{array}$ \\
\hline PI(D) controllers & $\begin{array}{l}\text { Implemented as discrete } \\
\text { controllers (works in } \\
\text { conjunction with } \\
\text { PWM/voltage output } \\
\text { actuators) }\end{array}$ & No & No & No & No & No & Yes, for temperature control \\
\hline $\begin{array}{l}\text { Voltage/current inputs for } \\
\text { external sensors }\end{array}$ & $\begin{array}{l}\text { Voltage/current/resistance } \\
\text { configurable input, } \mathrm{A} / \mathrm{D} \\
\text { conversion resolution of } \\
16 / 24 \text { bits }\end{array}$ & $\begin{array}{l}\text { Yes, bioelectric potential, } \\
\text { temperature, humidity }\end{array}$ & $\begin{array}{l}\text { Yes, temperature, humidity } \\
\text { and light sensors connected } \\
\text { to the } 12 \text {-bit } \mathrm{A} / \mathrm{D} \text { converter } \\
\text { of the monitoring unit }\end{array}$ & N/A & N/A & N/A & Yes, $\mathrm{O}_{2}$ and moisture sensors \\
\hline $\begin{array}{l}\text { Sensor with local display of } \\
\text { measurand values }\end{array}$ & $\begin{array}{l}\text { Yes, sensor devices with } \\
\text { LCD resolution } 400 \times \\
240\end{array}$ & No & No & No & No & No & No \\
\hline $\begin{array}{l}\text { Sensor with precalibrated } \\
\text { digital output transducers }\end{array}$ & $\begin{array}{c}\text { Yes, temperature, } \\
\text { humidity, pressure, } \mathrm{CO}_{2} \\
\text { level }\end{array}$ & No & No & N/A & $\mathrm{N} / \mathrm{A}$ & $\mathrm{N} / \mathrm{A}$ & $\begin{array}{c}\text { Yes, } \mathrm{CO}_{2} / \mathrm{RH} / \text { temperature } \\
\text { sensor, } \\
\mathrm{RH} / \text { temperature/pressure/VOC } \\
\text { concentration }\end{array}$ \\
\hline Remote monitoring & $\begin{array}{c}\text { Yes, Ethernet gateway } \\
\text { with embedded server } \\
\text { and TCP/IP connection } \\
\text { to dedicated computer } \\
\text { software } \\
\end{array}$ & No & No & Yes & $\begin{array}{l}\text { Yes, through Internet } \\
\text { Gateway }\end{array}$ & $\begin{array}{l}\text { Yes, connected to a cloud } \\
\text { platform through a Raspberry } \\
\text { Pi module }\end{array}$ & Yes, through a web server \\
\hline $\begin{array}{l}\text { Remote configuration of the } \\
\text { sensors }\end{array}$ & $\begin{array}{l}\text { Offset, gain, averaging } \\
\text { and median filter } \\
\text { lengths are configurable } \\
\text { for each measurand }\end{array}$ & No & No & No & No & No & N/A \\
\hline
\end{tabular}

${ }^{1}$ N/A-information Not Available / feature Not Applicable. 


\section{Results}

\subsection{Hardware Architecture}

The proposed ACS is organized in accord with a distributed control architecture exemplified in Figure 7.

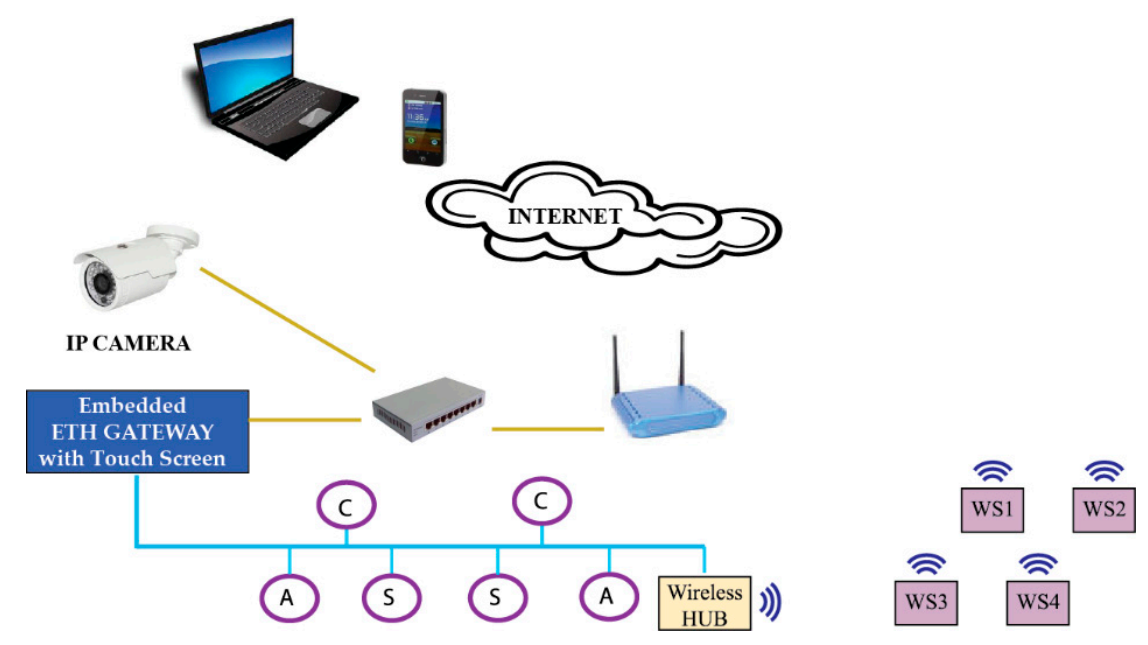

Figure 7. System architecture based on web services (C/S/A-controller/sensor/actuator nodes, WS1-4-wireless sensor nodes, Eth-Ethernet) (after [15]).

The sensing nodes are implemented in two versions: for wired or for wireless communication.

The wired versions use a four-pin connector: two wires for RS-485 communication and two wires for direct current (DC) power. Their communication protocol is Modbus-compliant. The basic behavior of a sensing node is described in Figure 8.

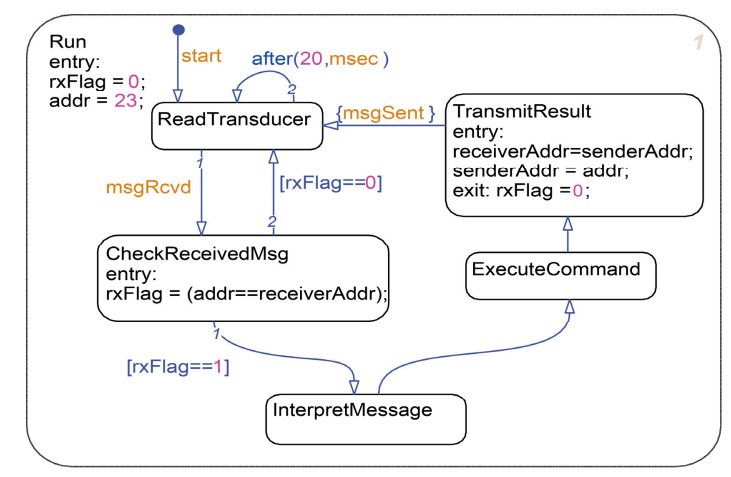

Figure 8. Sensor state machine (addr-address on the bus, msgRcvd/msgSent-message received/sent events, rxflag-boolean flag indicating reception of a message addressed to this node) [15].

Three types of sensing units were developed for characterizing the air inside the greenhouse: (a) air temperature and relative humidity $(\mathrm{RH})$ sensor; (b) air temperature, $\mathrm{CO}_{2}$ content and humidity sensor; and (c) air temperature, $\mathrm{CO}_{2}$ content, absolute pressure and humidity sensor. The third type also integrates a light intensity sensor (Figure 9). Digital output transducers, factory precalibrated, are used for temperature and humidity measurements. $\mathrm{CO}_{2}$ content is measured with a nondispersive infrared (NDIR) technology sensor. Their specifications are grouped in Table 4. 
Table 4. Accuracy specifications for the sensing devices.

\begin{tabular}{cccc}
\hline & Measurement Range & Accuracy & Operating Range \\
\hline $\mathrm{CO}_{2}$ & $\begin{array}{c}400 \text { to } 5000 \mathrm{ppm} \text {; extended } \\
\text { range up to } 10,000 \mathrm{ppm}\end{array}$ & $\begin{array}{c} \pm 30 \mathrm{ppm}+3 \% \text { of reading (extended range } \\
\pm 10 \% \text { of reading) in the conditions of } 15 \text { to }\end{array}$ & $\begin{array}{c}0 \text { to } 50{ }^{\circ} \mathrm{C}, 0 \% \text { to } 85 \% \mathrm{RH} \\
\text { (noncondensing) }\end{array}$ \\
Light & 0.015 to 64,000 lux & $35^{\circ} \mathrm{C}$ and $0 \%$ to $80 \% \mathrm{RH}$ & -20 to $85^{\circ} \mathrm{C}$ \\
Relative Humidity & $0 \%$ to $100 \%$ & $\pm 10 \%$ of reading & -20 to $85^{\circ} \mathrm{C}$ \\
Temperature & -20 to $85^{\circ} \mathrm{C}$ & $\pm 2 \%(10 \%$ to $70 \%$ ), $\pm 3 \%$ (Maximum) & -20 to $85^{\circ} \mathrm{C}$ \\
Absolute Pressure & 300 to $1050 \mathrm{hPa}$ & $\pm 0.2{ }^{\circ} \mathrm{C}$ (Typical), $\pm 0.4{ }^{\circ} \mathrm{C}$ (Maximum) & \pm to $40{ }^{\circ} \mathrm{C}$ \\
\hline
\end{tabular}

RH-Relative humidity
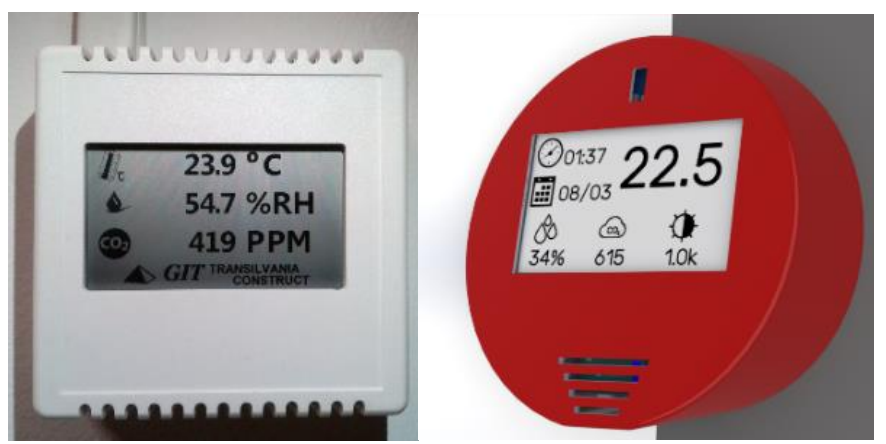

Figure 9. Sensing units for air temperature, humidity and $\mathrm{CO}_{2}$ content.

The soil temperature sensors were developed based on platinum resistive transducers (Pt1000) in both wired and wireless versions. A 16-bit analog-to-digital converter and $0.1 \%$ reference resistor guarantee an absolute error lower than $0.4{ }^{\circ} \mathrm{C}$ in the range of -10 to $40{ }^{\circ} \mathrm{C}$.

The soil water content sensors were developed based on the capacitive sensing method. Different transducer geometries were designed in SolidWorks ${ }^{\circledR}$ (Dassault Systèmes) and the simulation of the transducer assembly was performed in COMSOL Multiphysics ${ }^{\circledR}$ (COMSOL, Inc.) for iterative optimization of the component dimensions so that the final configuration (Figure 10) would reach a capacitance in the tens of picofarads while in water.
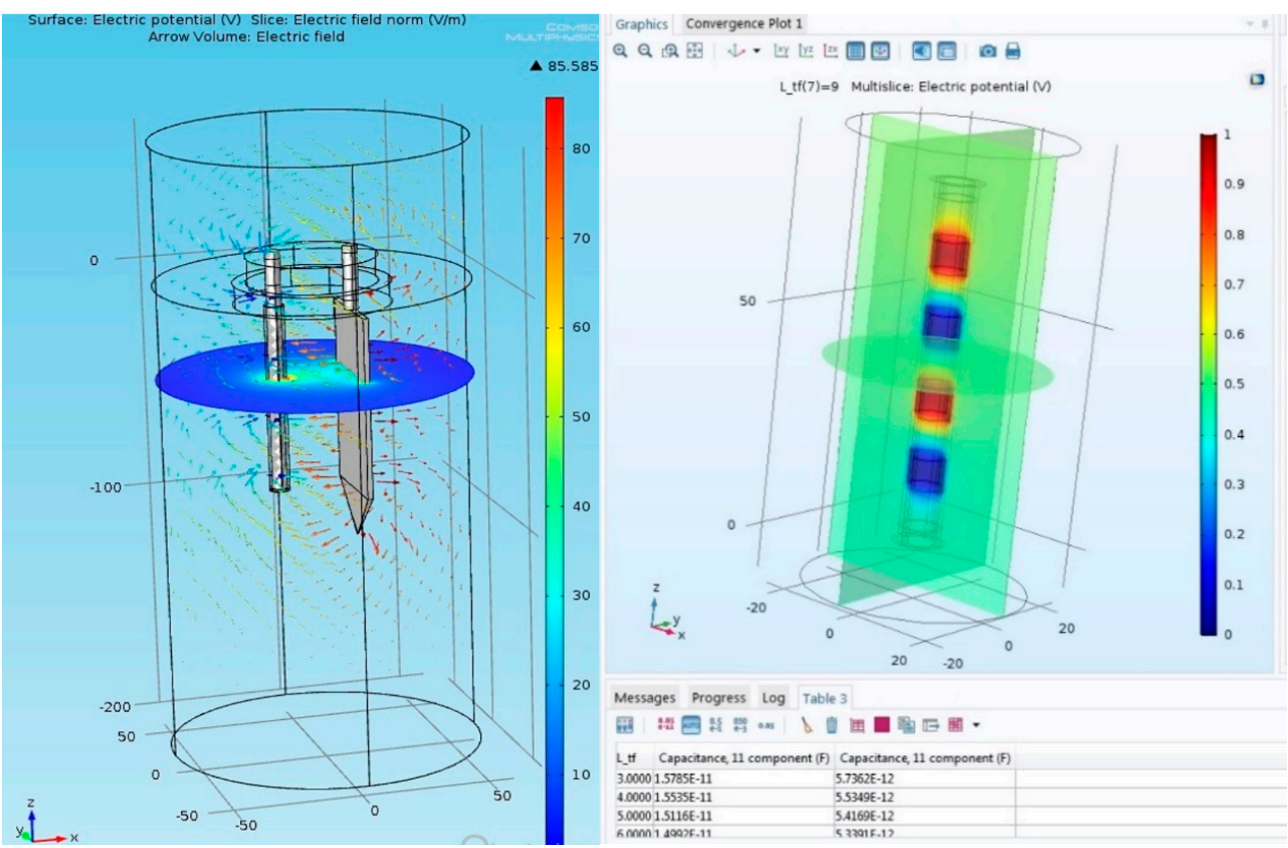

Figure 10. Simulation of the electric field and capacitance computing using COMSOL Multiphysics. 
The transducers are interfaced with an 8-bit low-cost microcontroller that provides offset calibration. The measured values are wirelessly transmitted through a $2.4 \mathrm{GHz}$ transceiver toward the wireless hub. Maximum capacitance measurement error in the temperature range of 0 to $50{ }^{\circ} \mathrm{C}$ is $4 \%$. The operation is powered by a rechargeable coin battery.

The calibration was done using the gravimetric technique (Figure 11) for both electrode configurations (Figure 12).

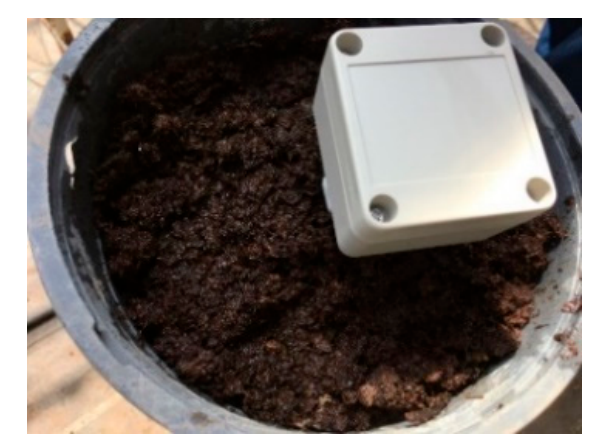

Figure 11. Soil water content measurement during calibration.

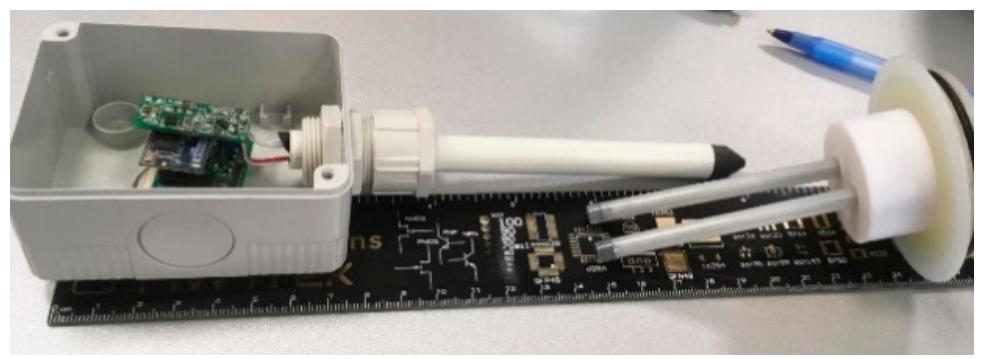

Figure 12. One-rod and two-rod sensor configurations.

The controller nodes provide direct logic (relay) outputs in two versions: five outputs and eight outputs. Their architecture and realization are depicted in Figure 13.
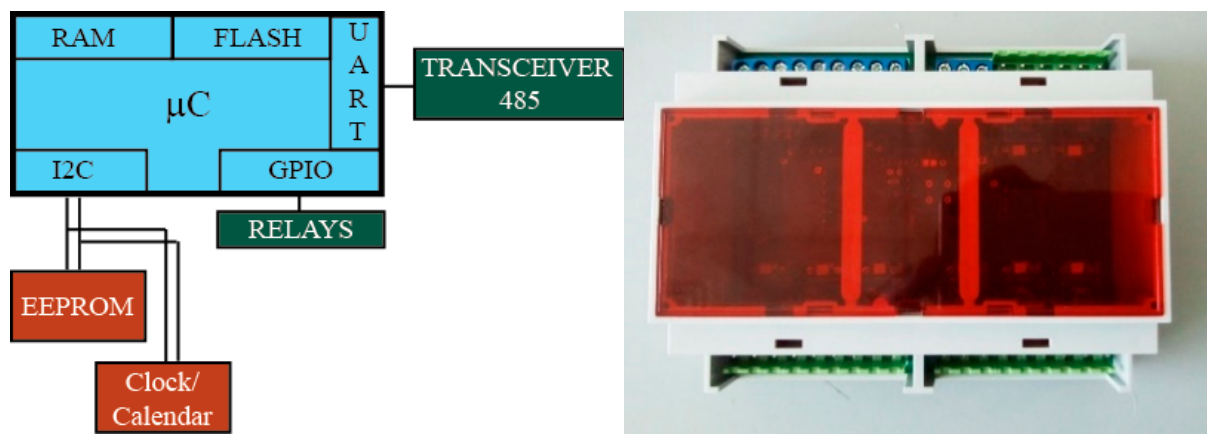

Figure 13. Controller nodes (UART-Universal Asynchronous Receiver-Transmitter, GPIO-General Purpose Input/Output, I2C Inter-Integrated Circuit, EEPROM-Electrically Erasable Programmable Read Only Memory).

The actuator nodes are intended for interfacing with voltage-controlled actuators and are realized in accord with the schematic of Figure 14. Their input value is received as a bus message with the significance of a percentage (0-100\%) that is linearly translated in $0-5 \mathrm{~V}$ or $0-10 \mathrm{~V}$ ranges. 


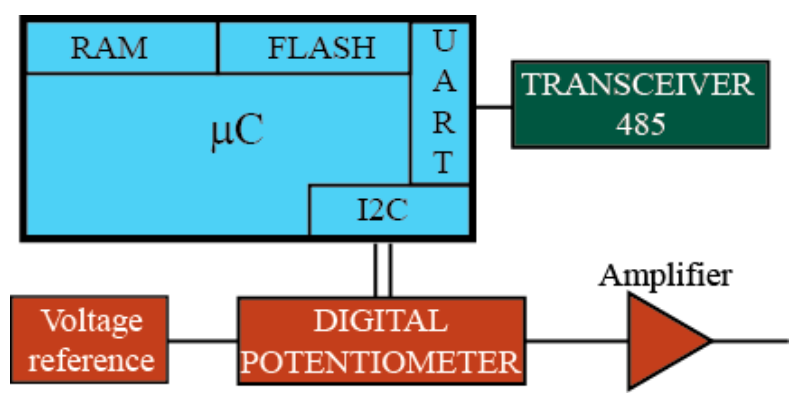

Figure 14. Actuator node.

The gateway node is the node with the most complex functionality, as indicated in Figure 15. Its physical realization is presented in Figure 16 together with its embedded web server functionality.

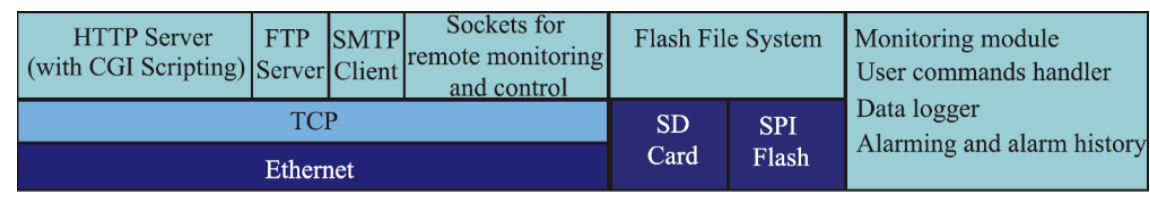

Figure 15. Functionalities of the Ethernet gateway module (HTTP-Hypertext Transfer Protocol, CGI-Common Gateway Interface, FTP-File Transfer Protocol, SMTP-Simple Mail Transfer Protocol, SPI-Serial Peripheral Interface, TCP-Transmission Control Protocol) [15].

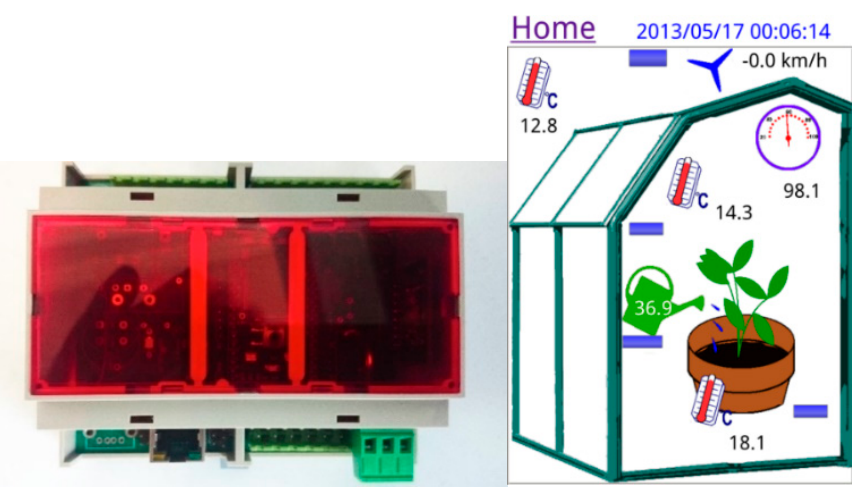

Figure 16. Ethernet gateway module and the web page for remote monitoring and control, provided by its embedded web server as seen on smartphone.

Following the paradigms of industrial system health management, a low-cost system was devised in order to detect functionality anomalies (fault detection) and to support preventive maintenance and self-diagnosing capabilities for the electromechanical actuation systems typically found in a greenhouse. The large majority of these actuators are driven by direct current (DC) or alternate current (AC) electric machines.

The identification of the electrical and mechanical faults of electrical-motor-driven actuators should start from the fact that most common failure modes are bearing failure, stator winding failures, rotor failures, faults in rolling element bearings and faults in the gearing mechanism. The proposed setup (Figure 17) addresses this through the motor current signature analysis (MCSA), vibration signature analysis (VSA) and operational temperature monitoring. These algorithms are based on local collection of waveforms by low-cost sensors realized with 8-bit microcontrollers, micro-electromechanical system (MEMS) accelerometers, integrated digital output temperature transducers and transmission of the samples in a wireless manner toward a more powerful 32-bit processor node (module with hardware identical with that of the hub) for running the data analysis algorithms. 

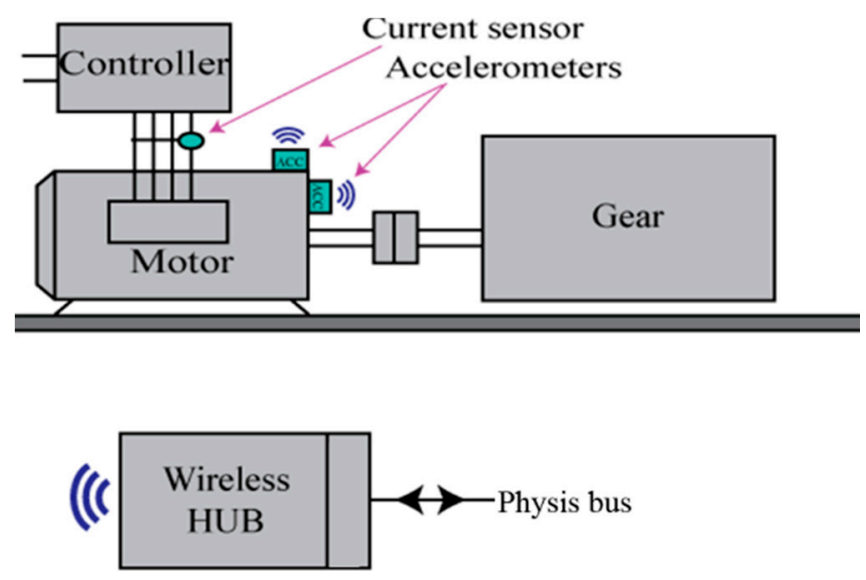

Figure 17. Setup for actuator condition monitoring.

The wireless hub is realized with a 32-bit ARM (Advanced Reduced Instruction Set Computer-RISC-Machines) processor and uses the CyFi network protocol, forming an N:1 star network. It combines Direct Sequence Spread Spectrum (DSSS) modulation, frequency agility and complex link management algorithms for dynamic change in real time of the operating channel, data rate and output power. It utilizes the unlicensed $2.4 \mathrm{GHz}$ industrial, scientific and medical (ISM) band and has the capability of addressing up to 250 nodes.

\subsection{Software Architecture} $Q t[16]:$

A series of applications for real-time monitoring of environmental parameters were developed in

- Configurator, a graphical editor which allows creation and editing of configurations that represent the spatial placement and the properties of each node of the multidrop networks;

- Monitor, a console application which allows, based on the network description file, monitoring of the network nodes by usage of TCP/IP sockets for connecting to each gateway defined in the configuration, periodically requesting the current values of the network nodes, and storage of the values;

- Inspector, an application offering, in addition to an interface for visualization, comparison and printing of the record history, both an abstract image of the system and a view of the physical location of the network nodes in the greenhouse space, assuring easy localization and referencing of the monitored nodes;

- Manager, an application that facilitates easy configuration and maintenance of the network nodes;

- Remote Transfer Interface and Visualisation Interface, applications that facilitate downloading of the archived data from a gateway module and graphical visualization of the downloaded data.

Network configurations are stored in XML format and contain representations of all the network nodes and their properties. Nodes from multiple multidrop networks can be represented in a configuration, each node being associated with the corresponding gateway module that interfaces the subnet (the example configuration of Table 5 explains the description related to a soil moisture sensor and to a gateway module). The files generated and exchanged by applications are described in Figure 18. 
Table 5. Example configuration for a soil moisture sensor and a gateway module represented in XML format.
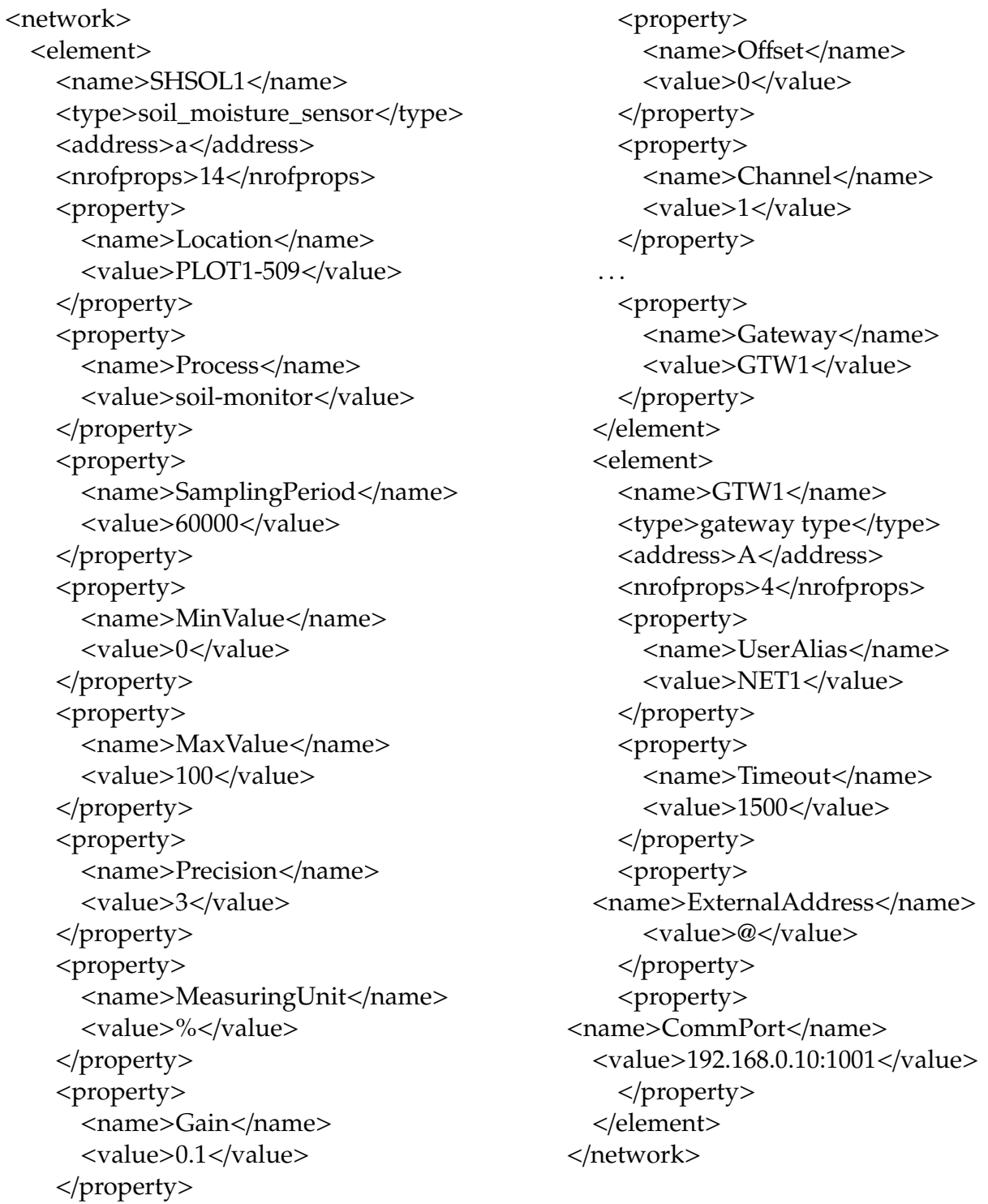

\subsubsection{Implementation of the Crop Planning Module}

For defining the desired profiles of the controlled variables, experiments with a first version of an application, called Process Editor, are mentioned in [13]. The application was extended, allowing a set of processes (up to 8) to be defined and saved.

Two types of processes may be defined: bipositional (on/off control) and continuous (P/PI control). A phase is characterized by properties such as name (string for unique identification of a phase into the process), phase type (maintain/control/idle) and phase duration.

Since each specific plant culture may require different regimes for watering, lighting, heating/cooling, humidifying/dehumidifying and $\mathrm{CO}_{2}$ addition, profiles that dictate the evolution in time of the reference values are defined for each control variable. These are specified for a $24 \mathrm{~h}$ cycle (see Figure 19). 


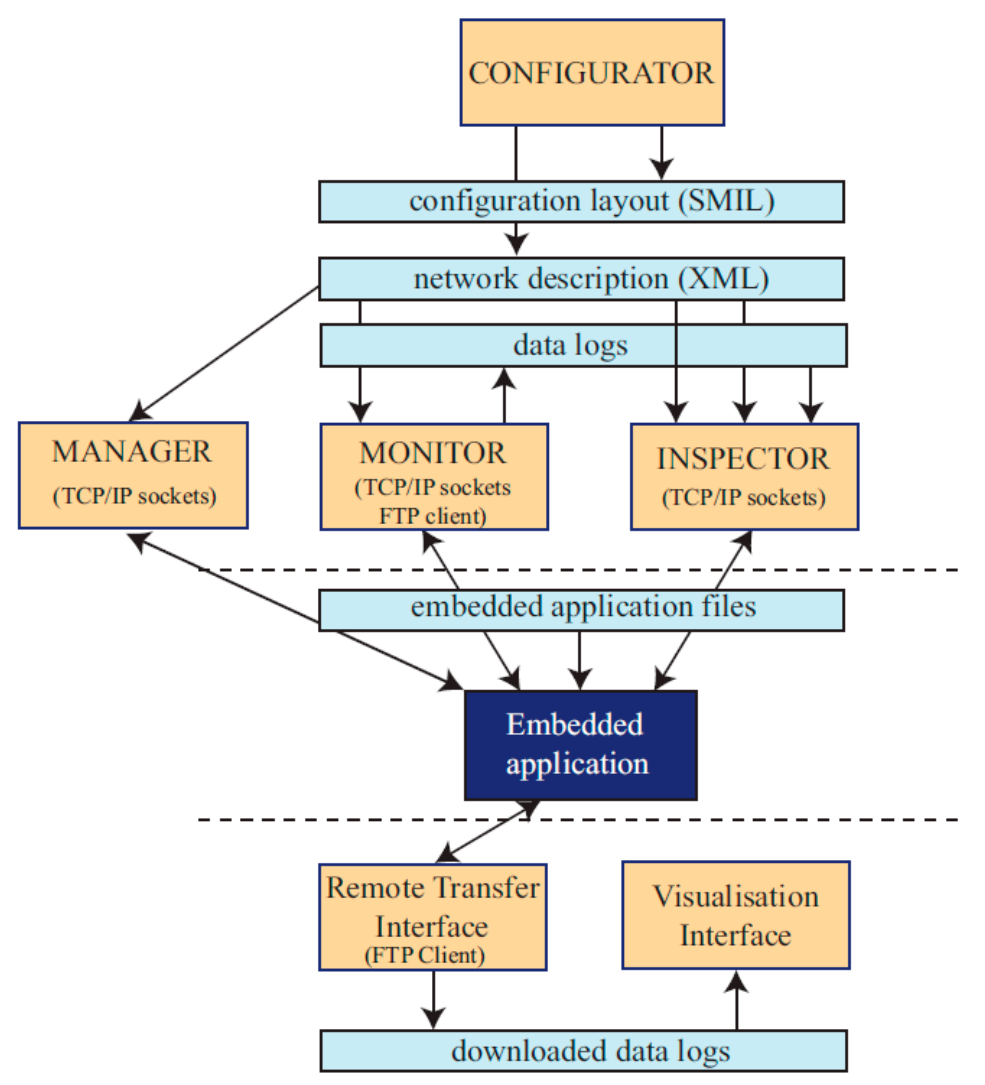

Figure 18. Files generated and exchanged by applications [16].

The information that has to be transferred into the controller for obtaining the prescribed profiles is represented as a set of processes.

Depending on the type, the phase may have specific properties. An idle phase does not present particular properties (during this phase the controller module on which the process will run does not change the actuator command).
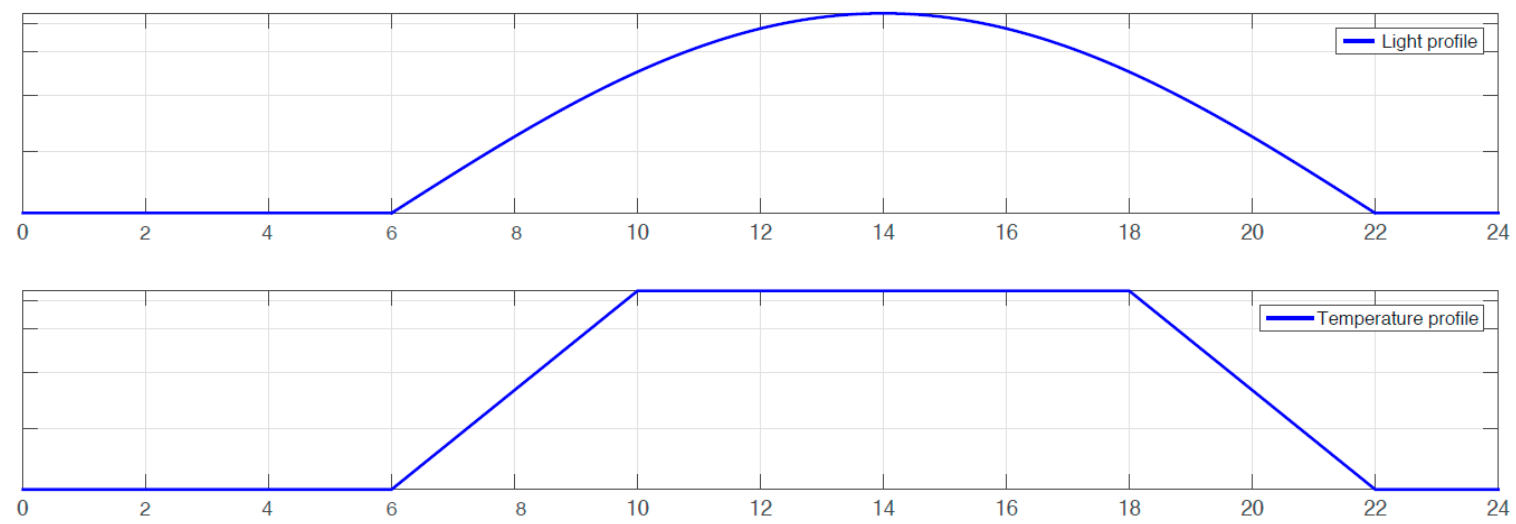

Figure 19. Example of light and temperature profiles specified for a $24 \mathrm{~h}$ cycle.

A control phase requires specifying the value for actuator command (on/off or $0-100 \%$ depending on the type of process).

A maintain phase contains information about the input channel (controlled variable) and the desired value to be tracked for that channel.

In the case of an on/off process, two additional input channels may be defined, along with the way in which the output should be computed: $\mathrm{cmd}=\mathrm{f}\left(\mathrm{Ch}_{1}, \mathrm{Ch}_{2}, \mathrm{Ch}_{3}\right.$, logic). 
For example, if the temperature reference value is considered associated in a phase to the regulating action of opening/closing of a window, the command of the actuator can be further conditioned by external factors such as wind speed and rain intensity.

The platform that allows that feedback to the control loops is provided through a spatial averaging strategy by the association of multiple sensor output channels to the same input channel of a controller through the specification of the sensor addresses list and of the corresponding weights.

For a P/PI process, one input channel can be specified, with the remaining space in the memory allocated to a phase being used for storing parameters of the controller.

\subsubsection{Implementation of the Interface Block Mechanisms}

Another application, called Process Loader was implemented; this application allows (based on a file specifying the network configuration and a process set) associating each process to a control variable and to an actuator, saving/importing of this type of configuration and uploading/downloading of configurations to/from a selected network controller.

The processes have a duration of $24 \mathrm{~h}$ and consist in a sequence of phases (up to 12). Each process is saved in XML format and contains information related to the process and to each phase of the process. For defining a set of processes, an XML file is used that specifies the process file names belonging to a specific set.

These types of profiles may be defined at the level of the Process Editor application as staircase approximations like the one shown in Figure 20 with blue color, and a piecewise linear (PWL) approximation may be implemented at the level of the controller, resulting in a profile like the one indicated in Figure 20 with red color.

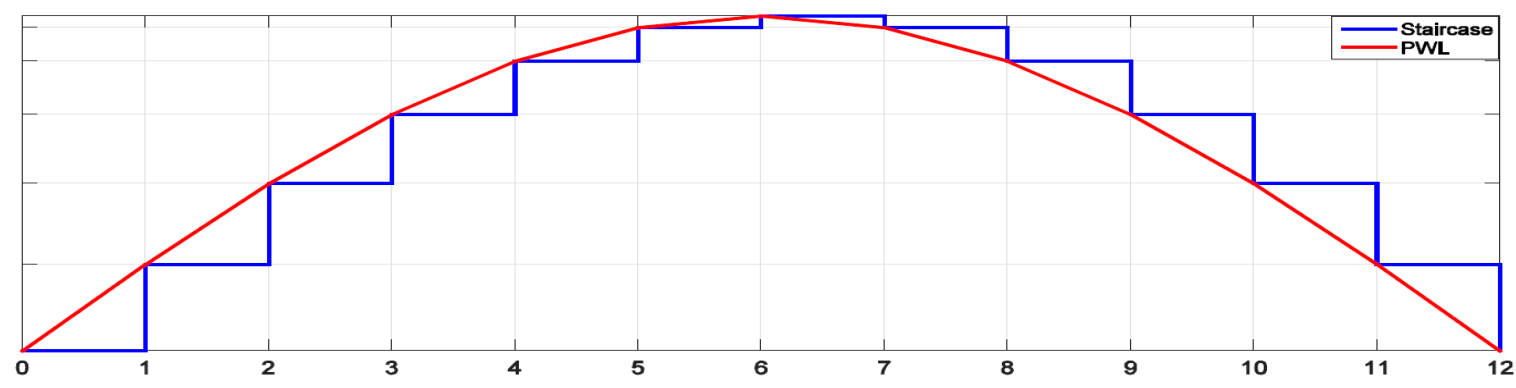

Figure 20. Example of staircase and piecewise linear (PWL) approximations for a continuous profile.

\subsubsection{Alarms and Alarm History}

The platform implements a system that facilitates representation and evaluation of user-defined alarm conditions, represented using first-order formulas (Table 6) or second-order functions.

Table 6. Format of a first-order alarm condition [16].

\begin{tabular}{cccc}
\hline Condition ID & Channel & Operator & Threshold \\
\hline condition_index & element_name & $<,>,=, \geq, \leq$ & Value \\
\hline
\end{tabular}

The second-order alarms are Boolean functions of primary conditions (up to four) expressed in canonical disjunctive form condition_order2 $=\mathrm{f}(\mathrm{C} 1, \mathrm{C} 2, \mathrm{C} 3, \mathrm{C} 4)$. Each secondary alarm condition requires specification of a mask (coding on two bytes the positions corresponding to valid rows in the truth table associated with the canonical form) and the list of primary conditions considered.

For example, considering a configuration with two controllers responsible for heating a room based on the same sensor value and on predefined set-points, a second-order alarm condition can be formulated as follows: trigger the alarm when the temperature in the room is less than $20^{\circ} \mathrm{C}$ and the 
The neural network models are trained in the open-source neural-network library Keras (TensorFlow backend) and exported to files. The model is then imported in STM32Cube.AI software tool and used to generate optimized code for the targeted microcontroller. The generated neural network library can then be deployed on the microcontroller.

\subsection{Experiments and Results}

The Process Editor interface is presented in Figure 22.

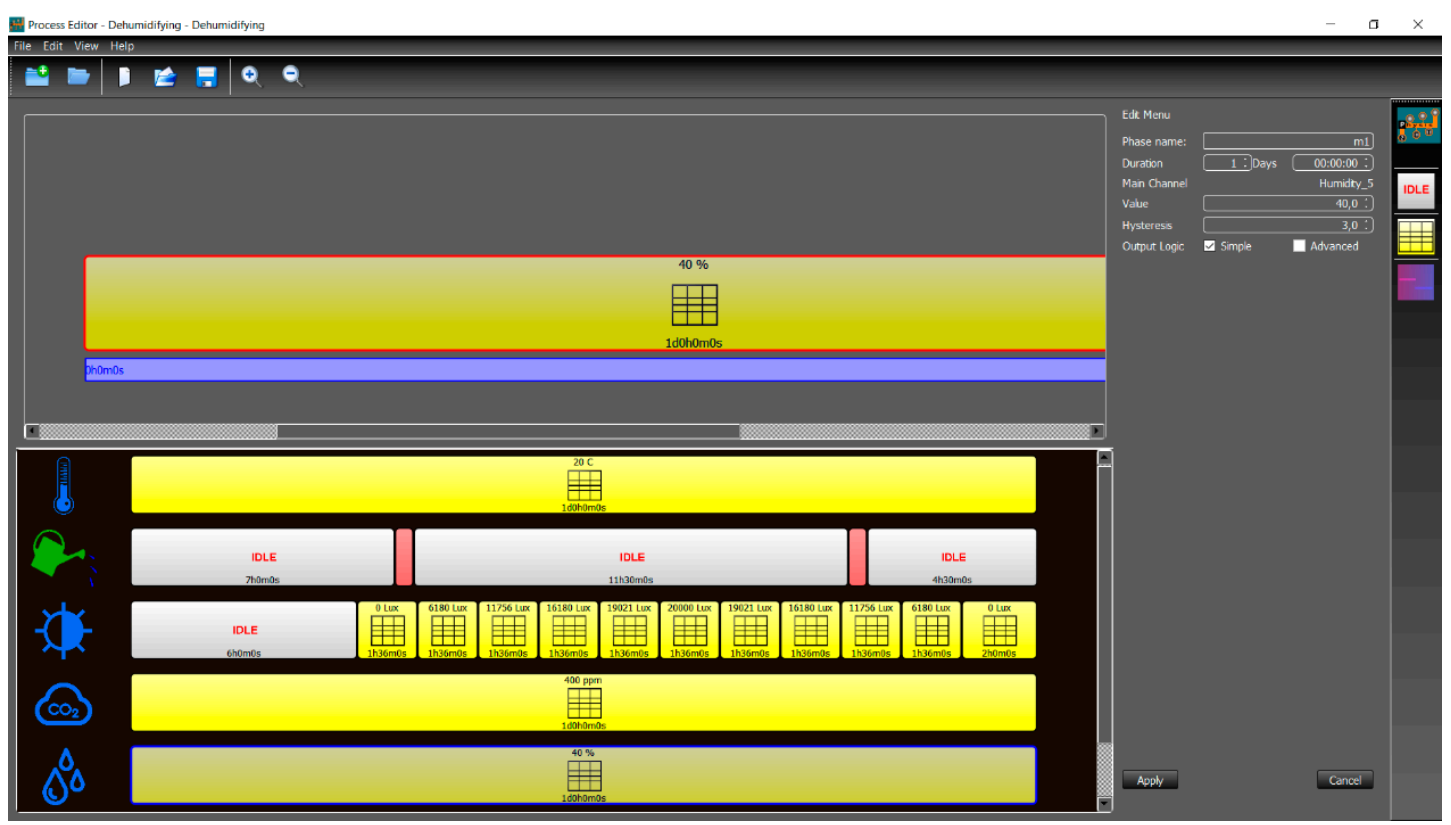

Figure 22. Process Editor interface.

The compacted form is transferable through the Process Loader application (Figure 23).

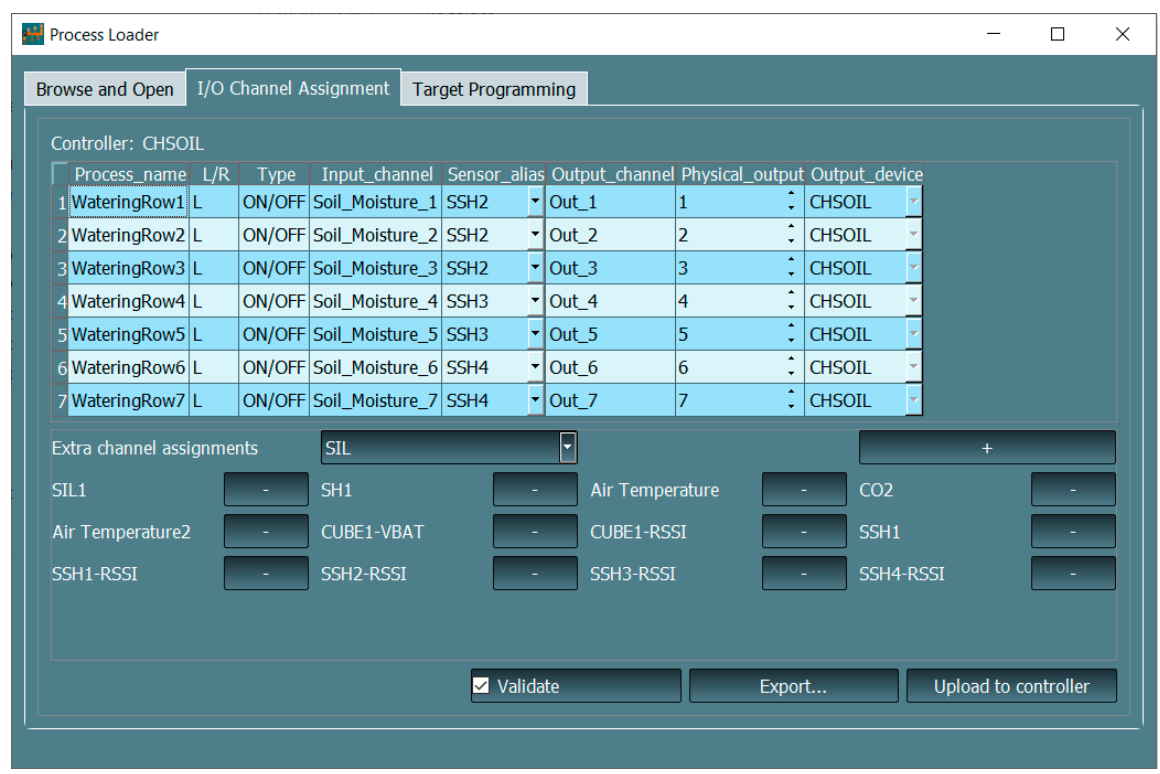

Figure 23. Process Loader interface.

Remote monitoring is available in a simple form through the embedded web server of the gateway, but advanced archiving and visualization functionalities are provided through the Remote Transfer 
interface (Figure 24). The visualization application might be used not only for examining the sensor records (Figures 25 and 26), and was validated in different plant monitoring projects (like water stress and overheating, Figure 27). This may be used also for verifying the controller response (Figure 28), by inspecting the graphs associated with output channels.

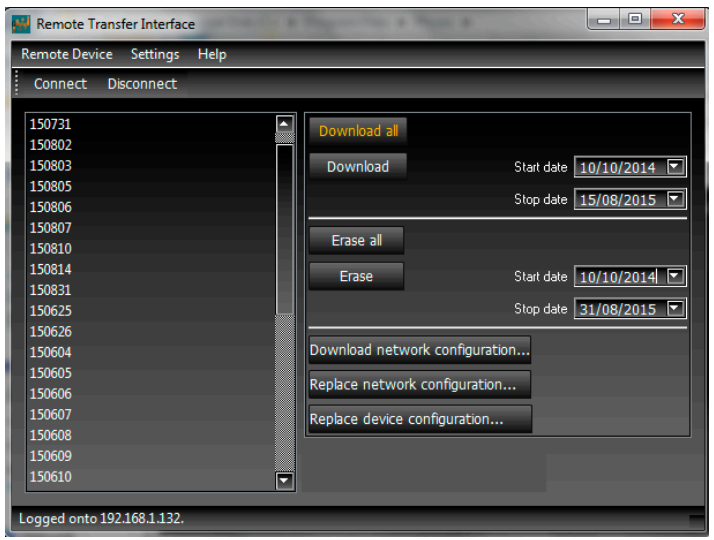

Figure 24. Remote Transfer interface.

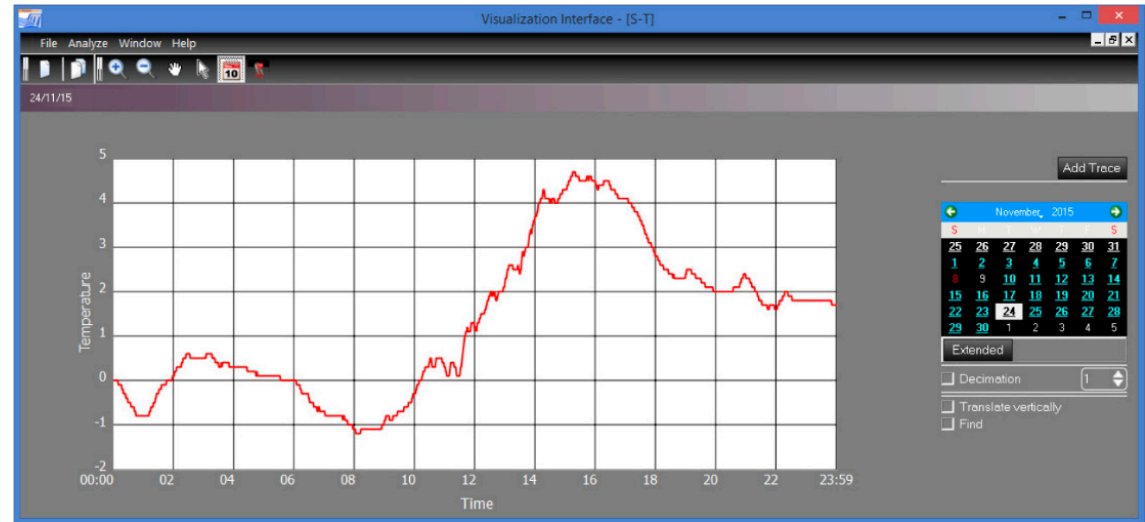

Figure 25. Example of visualization of sensor records for one day (external air temperature).

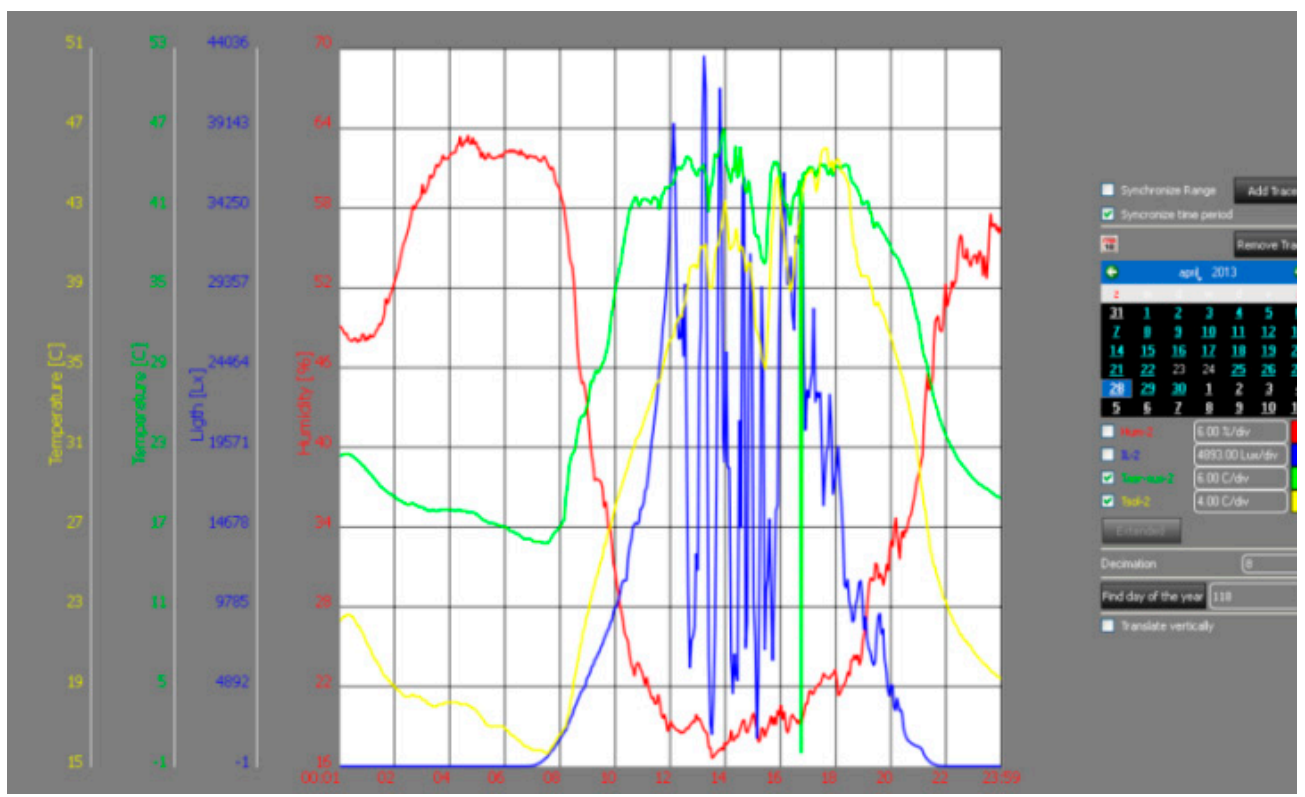

Figure 26. Environmental parameter dynamics monitored in the fourth day of water stress induction. 


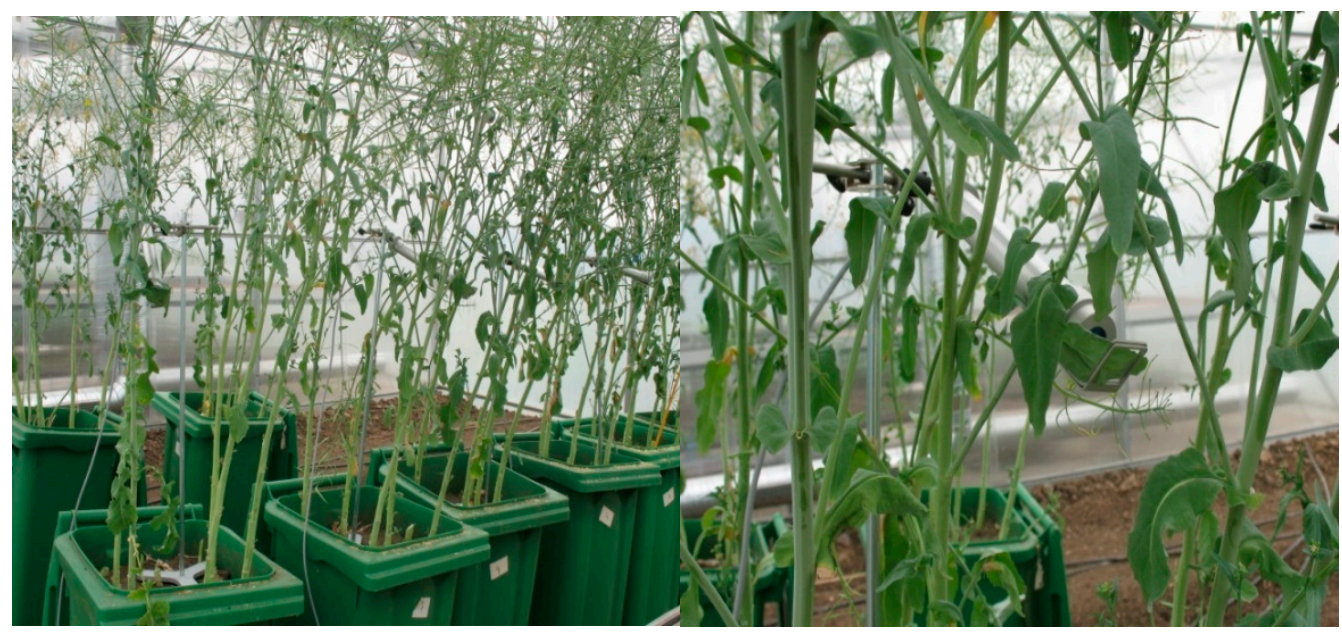

Figure 27. Rapeseed oil (Brassica napus L.) plants subjected to water stress and overheating.

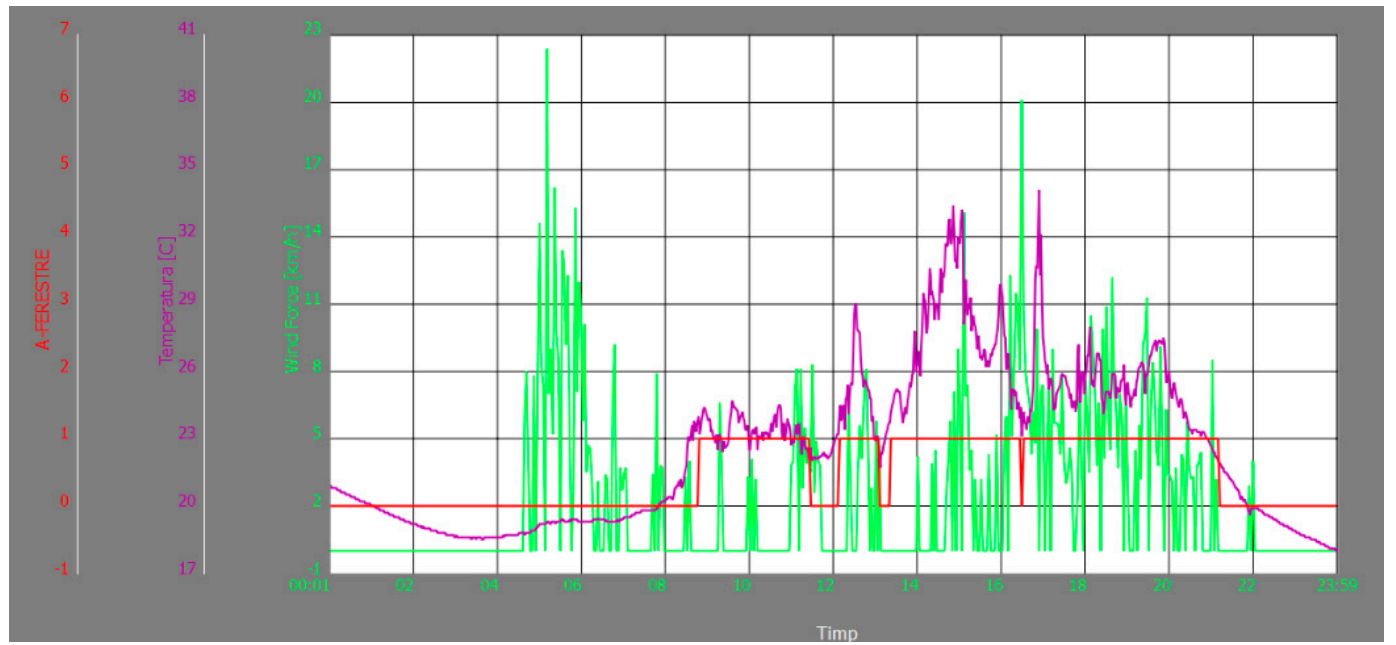

Figure 28. Window control based on internal temperature and wind speed bounds.

3.4.1. Experiments for Estimating Environmental Variables in Smart Sensor Networks with Faulty Nodes

The datasets collected by the Physis platform for a smart sensor network usually contain 1-min sampled records of environmental parameters. For the experiment, two sensors were used: an air temperature and relative humidity sensor placed indoors $\left(T_{i}, H_{i}\right)$ and an air temperature sensor placed outdoors $\left(T_{\text {ext }}\right)$. Figure 29 presents the experimental dataset containing records for 11 successive days.

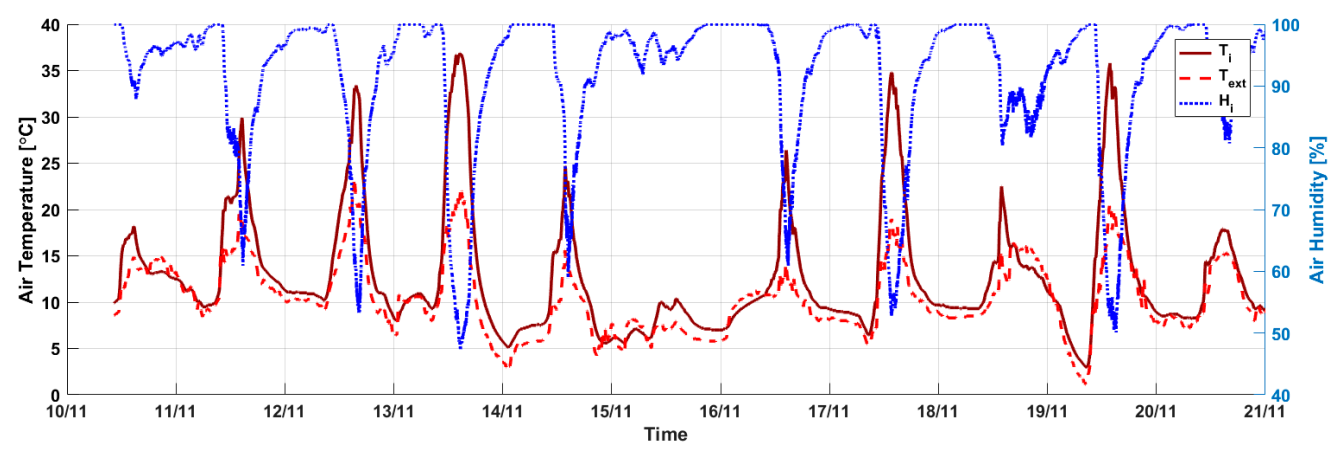

Figure 29. Recorded dataset $\left(T_{i}, H_{i}\right.$-indoor air temperature/ relative humidity, $T_{\text {ext }}$-outdoor air temperature) [66]. 
A first experiment considered estimation of the inside air temperature based on the values of the other variables at prior time moments $\left(\hat{T}_{i}[k]=f\left(T_{\text {ext }}[k-1], H_{i}[k-1]\right)\right)$. The results obtained using a LSTM model with 12 neurons are presented in Figure 30.

A second experiment considered 1-day-ahead prediction of the inside air temperature based on the other sensor values recorded during seven days $\left(\left[\hat{T}_{i}[k], \hat{T}_{i}[k+1], \ldots, \hat{T}_{i}[k+N]\right]=\right.$ $\left.f\left(T_{i}[k-7 N], T_{\text {ext }}[k-7 N], H_{i}[k-7 N], \ldots, T_{i}[k-1], T_{\text {ext }}[k-1], H_{i}[k-1]\right)\right)$. For reducing the number of records, the average of 30 successive records was used. The results obtained using a bidirectional LSTM model with 12 neurons are presented in Figure 31.

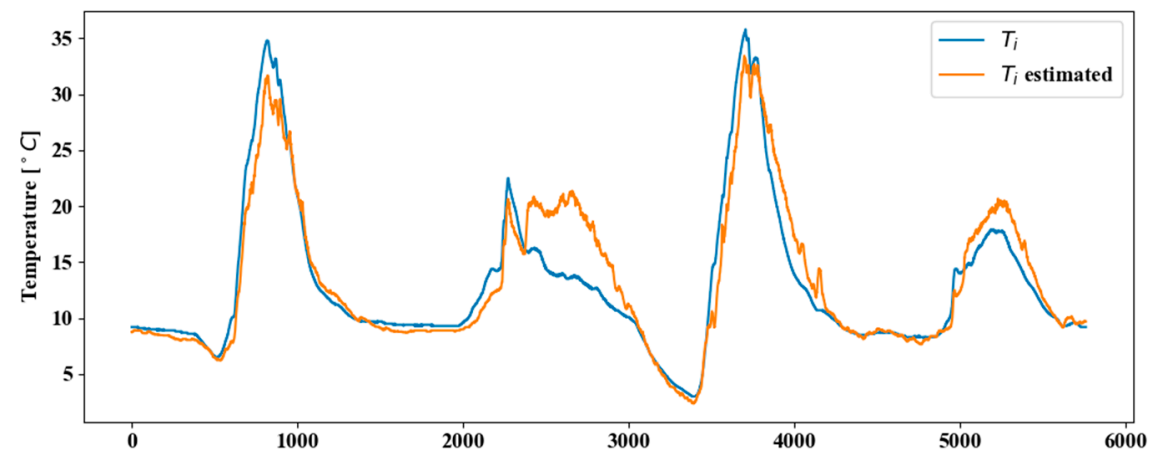

Figure 30. Estimated indoor vs. measured indoor temperature for the validation set (first experiment).

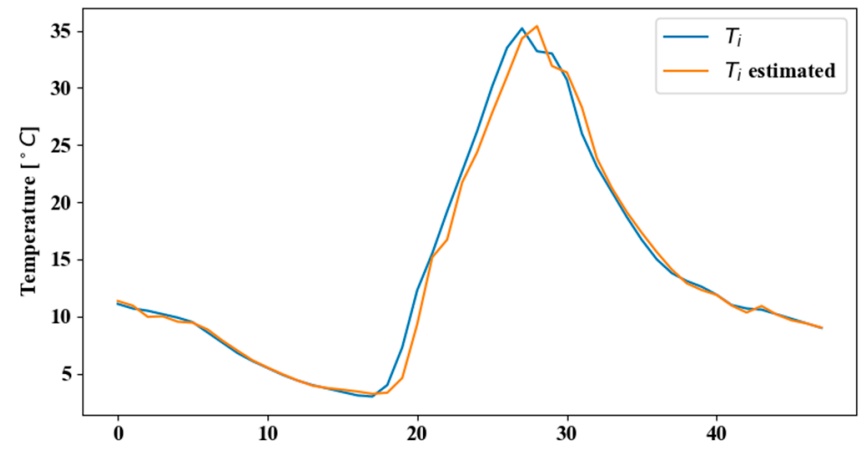

Figure 31. Estimated indoor vs. measured indoor temperature for the validation set (second experiment).

\subsubsection{Simulation of the Proposed Energy-Efficient Control}

The control structure presented in Section 2.9 was comparatively simulated for three different scenarios. The simulation results are presented in Figure 32.

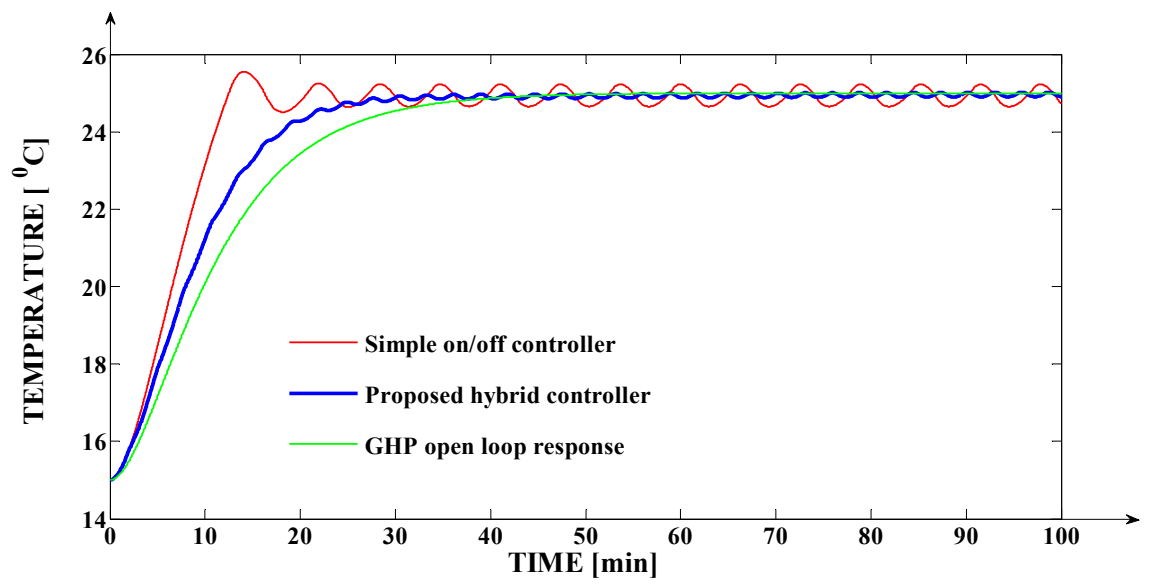

Figure 32. The simulation results obtained for the dynamics of the temperature inside the greenhouse. 
The main objective of the previous simulations was to consider the temperature increase from the value of $15{ }^{\circ} \mathrm{C}$ to the value of $25^{\circ} \mathrm{C}$.

The response highlighted with green color corresponds to the GHP open-loop response (obtained if the TS is not connected in the system and setting the appropriate constant value for the $\mathrm{m}(\mathrm{t})$ signal (modulation index) which generates the imposed temperature increase). Obviously, the mentioned $\mathrm{m}(\mathrm{t})$ constant value is previously computed only for the considered case. In the context of changing the setpoint signal value, the open-loop control becomes inefficient (the steady-state error cannot be avoided in this case).

The response highlighted with red color corresponds to the case in which hybrid controller (HC) contains only the TPR and its hysteresis is appropriately set. From the previous figure, it can be seen that the obtained response is considerable faster than the open-loop one and that the temperature inside the greenhouse is controlled with acceptable tolerance near the imposed value (even in the case where the value of the setpoint signal is modified). The main disadvantages obtained in this case are that the response presents a consistent overshoot and the response oscillations near the imposed temperature ripple are significant (not unacceptable, but significant).

The response highlighted with blue color corresponds to the case of using the proposed HC (containing both C and TPR elements). The obtained response is faster than the open-loop one and the imposed temperature is tracked with high accuracy by the HC. Obviously, the response oscillations near the imposed temperature are much lower than in the case of using the simple on/off controller. Additionally, the overshoot is negligible in this case, an aspect which represents an important technological advantage. Considering a steady-state band of $\pm 2 \%$, in relation to the imposed temperature, the obtained settling time is comparable with the settling time obtained in the case of using the simple two-position controller. However, the settling time, in the case of the approached application, represents an important control performance but not a vital one (the vital performances are the obtained precision of the control system response in relation to the imposed reference temperature value, the overshoot and the energy saving).

As a consequence of avoiding the overshoot in the case of using the proposed $\mathrm{HC}$, in comparison with the case of using the simple two-position relay, the energy consumption of the HE is lower in the case of using the proposed HC. This aspect is proven by the simulations presented in Figure 33.

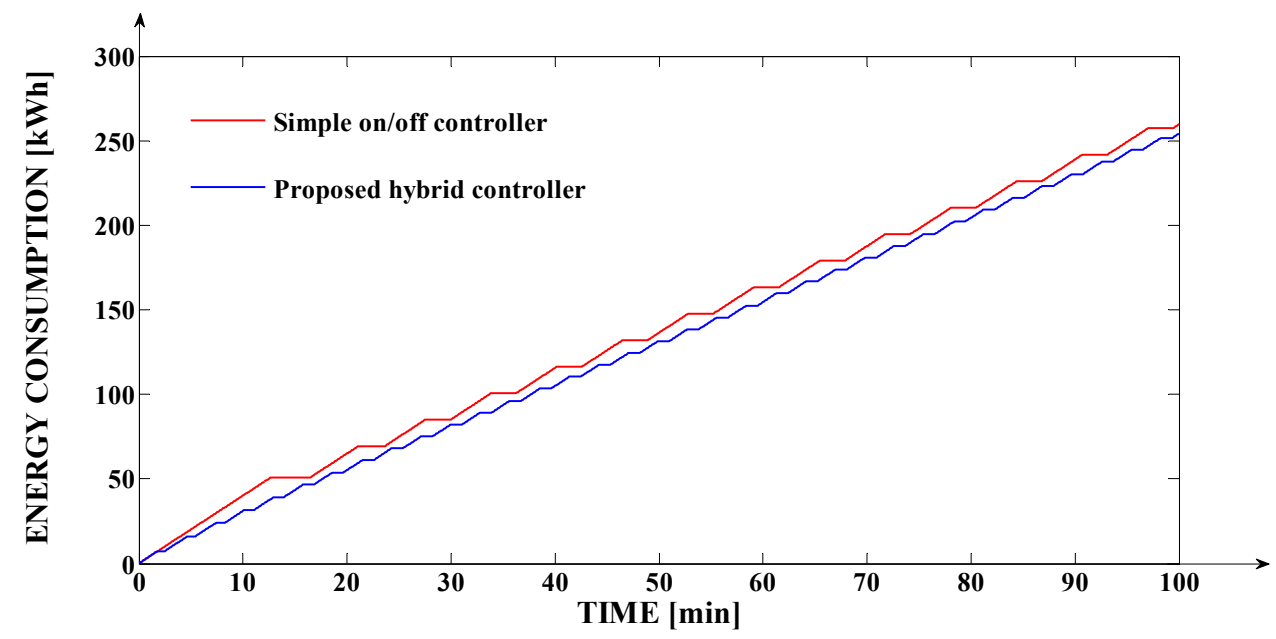

Figure 33. The energy saving analysis.

From the previous figure, the energy saving is obvious in the case of using the proposed HC (the blue energy curve is lower over the entire simulation than the red energy curve). In the first 100 min of the control system operation, the saved energy is equal to $5.3 \mathrm{kWh}$.

Considering all of the results above, the proposed control solution based on the $\mathrm{HC}$ is a viable one. 


\subsubsection{Experiments with the Actuator Faults Detection Setup}

Examples of waveforms recorded by the wireless acceleration sensors are shown in Figure 34.

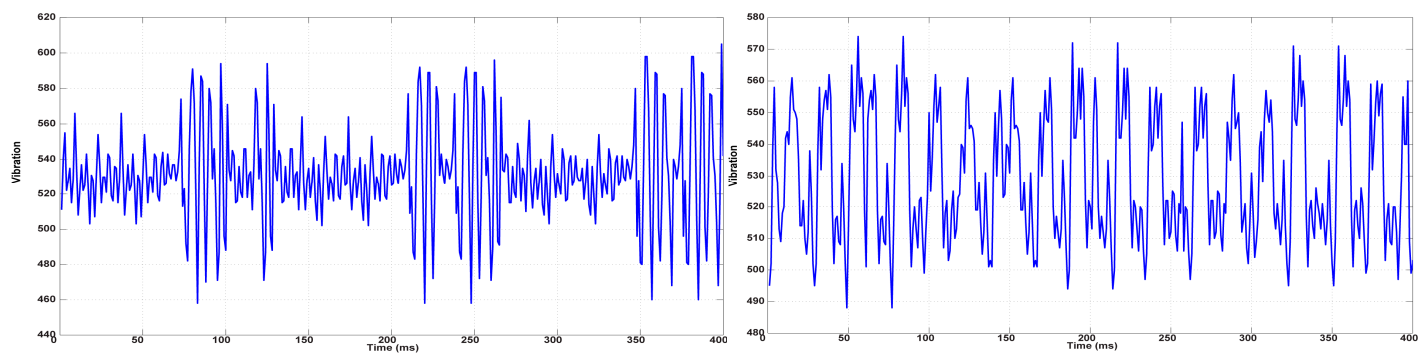

Figure 34. Vibration signal collected by the acceleration sensors for a faulty gear (left) and good gear (right).

Fault detection can be implemented based on spectral analysis of the collected digital sequences, as demonstrated in Figure 35.

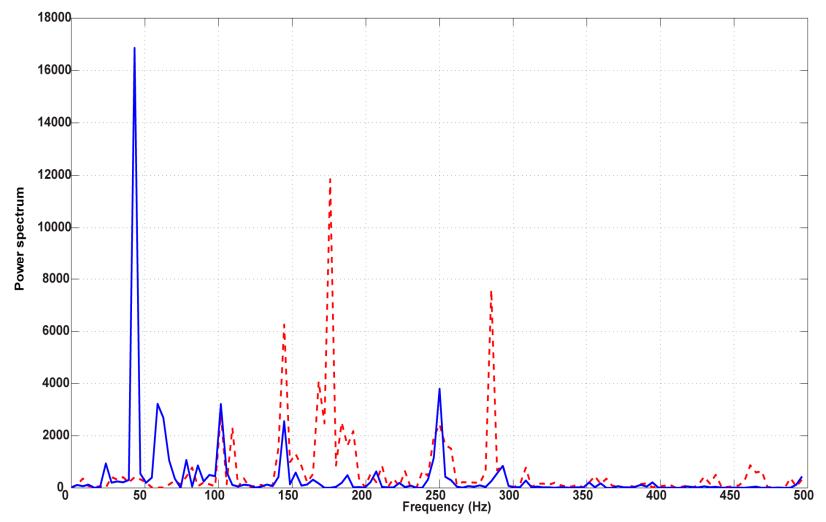

Figure 35. Spectrum comparison for the two vibration signals collected at the level of the wireless hub.

\section{Discussion}

This paper presents the experience of developing a low-cost architecture able to support environmental monitoring and control of remote greenhouses. The main environmental parameters are sensed with microcontroller-based smart sensors organized in wired and wireless networks.

In the proposed topology, only one node can send a message at a given moment, while the others are listening. A token-passing access method was implemented: a controller node interrogates its associated sensor nodes and then passes the bus master role to the next controller. The network latency is not noticeable for setups with up to 32 nodes: the interval between two samples requested by a controller from the sensor is less than $5 \mathrm{~s}$.

The fault tolerance of the distributed control network with a token-passing protocol was analyzed by simulating the activity of the control network nodes on the bus in the presence of individual node failures. Robustness to sensor failure was demonstrated through the ability to predict the 1-day ahead values for inside air temperature based on the measurements of all the variables collected in the previous 7 days.

The use of a single cable for supporting power delivery and RS485-based communication for all nodes in the network is a key advantage; there are issues and challenges associated with such a setup in terms of voltage drops, but the low-power, low-voltage sensing devices avoid these. The low power consumption was a key design constraint considered for all nodes: sensors, controllers, actuator interfacing modules, gateways and hubs. Low-power processing and energy saving strategies in the sensor firmware were used not only for the wireless (battery-powered) nodes but also for the wired 
ones in order to keep the average power for standard installations (one gateway, one hub, up to eight sensors, one controller)-less than $5 \mathrm{~W}$. When paired with an LTE router, such a setup can be easily powered by a small photovoltaic system (panel, charger and battery) for autonomous operation in monitoring of remote greenhouses without grid connection.

The proposed solution comes with the advantages of scalability, robustness and remote operation at an affordable price (see Table 8).

Table 8. Estimated values for the bill of materials (BOM) of the network nodes, as of March 2020.

\begin{tabular}{cc}
\hline Module & BOM Price in Euros (500 Units Volume) \\
\hline Gateway & 95 \\
Wireless hub & 92 \\
Sensing unit for air temperature, humidity, light and $\mathrm{CO}_{2}$ & 89 \\
Wireless temperature sensor & 39 \\
Wireless acceleration sensor & 42 \\
Wireless soil water content sensor & 75 \\
Controller (5 digital outputs) & 37 \\
\hline
\end{tabular}

Although basic alarm conditions are handled by the embedded application, an alarm editor and handler are available through the software application.

A suite of applications was developed for making the acquired data and the setting of the environment control regimes remotely available in real time via the Internet. They were built in such a way that executables can be generated on Linux, Windows and macOS platforms and user interfaces can be localized in different languages for improved user-friendliness.

\section{Conclusions}

The ACS introduced in the paper can be seen from two perspectives: it can be seen as a low-cost embedded platform able to support scalable distributed control networks to be deployed for processes that are not fast, and it can also be seen as a greenhouse environment control system that is "humanized" through the presence of a suite of software applications with flows and interfaces developed from a grower-centric perspective.

When compared with other low-cost or cost-effective implementations, the proposed system has several distinctive advantages.

The distributed control architecture allows easy scaling of the system (addition of new sensor/controller nodes), clear decoupling of the actuator driving hardware from the controller hardware, simultaneous multipoint sensing of the greenhouse volume, much larger distances between sensing points (Modbus on RS485 allows for hundreds of meters of cable segments) and better resilience to faults than in the case of single processor/controller approaches like that of [65].

Adherence to a well-established communication protocol like Modbus brings two primary benefits: first, interoperability is guaranteed for a large range of commercially available Modbus output sensors; second, for all major sensor communication protocols/standards, there is a bridge toward Modbus available as a commercial device, meaning that virtually every other type of sensor can be integrated in the proposed ACS.

Integrated multi-tier architecture allows easy remote programming of the environmental regimes and easy switching between crops, along with the abstraction of the hardware implementation and control algorithm details through the presence of the dedicated crop planning module.

The modular approach that groups a subnetwork around the gateway nodes gives high flexibility in configuration and scaling: small or experimental greenhouse installations can be realized in a low-cost manner with just one gateway managing several dozens of devices, while for large-scale setups (big production greenhouse fields) a second-level communication backbone can be easily realized with wired/wireless Ethernet switches and routers. 
Possibilities of electromechanical actuator fault detection were demonstrated within an affordable hardware setup. The alarm editing module allows much more complex alarm conditions than the case of simple growing controllers, supporting early detection of faults in heating, watering and ventilation systems.

Fault-tolerant behavior of the ACS was demonstrated by introducing a smart emulator module that can avoid extreme damage such as drought and freeze induced by malfunctions or communication failures of the sensors used in the control loops.

Author Contributions: Conceptualization, D.M. and N.S.; methodology, V.M. and R.L.S.; software, N.S. and A.L.; validation, R.L.S., T.V. and C.A.P.; investigation, D.M., N.S. and V.M.; writing - original draft preparation, N.S.; writing - review and editing, D.M.; project administration, D.M. and R.L.S. All authors have read and agreed to the published version of the manuscript.

Funding: This research received no external funding.

Acknowledgments: The authors are grateful for the financial support for publishing provided by the project "Ensuring excellence in RDI activities within USAMVBT", code 35PFE/2018, financed by the Ministry of Research and Innovation (MCI) through Program 1-Development of the national research and development system, Subprogram 1.2-Institutional performance, Institutional development projects-Projects to fund excellence in RDI.

Conflicts of Interest: The authors declare no conflict of interest.

\section{References}

1. SPAGNOL. Automation and Efficiency. Available online: https://www.spagnol.com/en-us/solutions/ greenhouse-automation (accessed on 27 April 2020).

2. Microgrow Control Systems. Available online: https://microgrow.com (accessed on 27 April 2020).

3. Solar Innovations. Greenhouse Environmental Control Systems. Available online: https: //solarinnovations.com/accessories/greenhouse-accessories/greenhouse-environmental-control-systems (accessed on 27 April 2020).

4. Autogrow. Automated Greenhouse. Available online: https://autogrow.com/your-growing-environment/ automated-greenhouse (accessed on 27 April 2020).

5. DigiKmet. Available online: http://digikmet.com/our-products/\#presaleform (accessed on 27 April 2020).

6. Sensaphone. Greenhouse Remote Monitoring Systems. Available online: https://www.sensaphone.com/ industries/greenhouse (accessed on 27 April 2020).

7. Monnit. Remote Monitoring Systems for Greenhouse Monitoring. Available online: https://www.monnit. com/solutions/greenhouse-monitoring (accessed on 27 April 2020).

8. Wadsworth Control Systems. Available online: https://wadsworthcontrols.com (accessed on 27 April 2020).

9. Rimol Greenhouse Systems. Environmental Controls. Available online: https://store.rimolgreenhouses.com/ Environmental_Controls_s/1846.htm (accessed on 27 April 2020).

10. ProBoard. GreenControl-GreenHouse Control System User's Manual V6.0. Available online: http: //www.proboard.pt/Site_en/include/GC_V60.pdf (accessed on 27 April 2020).

11. DENSO. Climate Control System for Greenhouse. Available online: https://www.denso.com/global/en/ products-and-services/Agriculture/climate-control-system-for-greenhouse/characteristic.html (accessed on 27 April 2020).

12. Softweb Solutions. Smart Greenhouse Monitoring Solution. Available online: https:/www.iotconnect.io/ smart-greenhouse-solution.html (accessed on 27 April 2020).

13. Moga, D.; Petreus, D.; Stroia, N. A low cost architecture for remote control and monitoring of greenhouse fields. In Proceedings of the 2012 7th IEEE Conference on Industrial Electronics and Applications (ICIEA), Singapore, 18-20 July 2012; pp. 1940-1944. [CrossRef]

14. Stroia, N.; Moga, D.; Barabas, Z. Web based monitoring of solar power systems. In Proceedings of the 2nd IFAC Workshop Convergence of Information Technologies and Control Methods with Power Systems (ICPS'13), Cluj-Napoca, Romania, 22-24 May 2013; Volume 2, pp. 131-136. [CrossRef]

15. Moga, D.; Stroia, N.; Petreus, D.; Moga, R.; Munteanu, R.A. Embedded Platform for Web-based Monitoring and Control of a Smart Home. In Proceedings of the 15th International Conference on Environment and Electrical Engineering, Rome, Italy, 10-13 June 2015. [CrossRef] 
16. Stroia, N.; Moga, D.; Vitan, E.; Cosovici, G.; Lungoci, C.; Kovacs, I.; Mircea, M. Internet based SCADA platform for monitoring strategic hydrotechnical structures. In Proceedings of the 20th IEEE International Conference on Automation, Quality and Testing, Robotics (AQTR), Cluj-Napoca, Romania, 19-21 May 2016. [CrossRef]

17. Li, T.; Zhang, M.; Ji, Y.H.; Sha, S.; Jiang, Y.Q.; Li, M.Z. Management of $\mathrm{CO}_{2}$ in a tomato greenhouse using WSN and BPNN techniques. Int. J. Agric. Biol. Eng. 2015. [CrossRef]

18. Teitel, M.; Atias, M.; Barak, M. Gradients of temperature, humidity and $\mathrm{CO}_{2}$ along a fan-ventilated greenhouse. Biosyst. Eng. 2010, 106, 166-174. [CrossRef]

19. Mehdi, D.; Mahmood, F.; Mahmood, B. Data Acquisition of Greenhouse Using Arduino. J. Univ. Babylon 2014, 22, 1908-1916.

20. Yuanping, S.; Lihong, X. Towards discrete time model for greenhouse climate control. Eng. Agric. Environ. Food 2017, 10, 157-170. [CrossRef]

21. Dingyi, L.; Ruihua, W.; Lihong, X. An Integrated Yield Prediction Model for Greenhouse Tomato. Agronomy 2019, 9, 873.

22. Sánchez, J.; Rodríguez, F.; Guzmán, J.; Arahal, M. Estimation of Solar Radiation for Tomato Water Requirement Calculation in Chinese-Style Solar Greenhouses Based on Least Mean Squares Filter. Sensors 2012, 12, 15244-15266. [CrossRef]

23. Zhang, D.; Zhang, T.; Ji, J.; Sun, Z.; Wang, Y.; Sun, Y.; Li, Q. Estimation of solar radiation for tomato water requirement calculation in Chinese-style solar greenhouses based on least mean squares filter. Sensors 2020, 20, 155. [CrossRef]

24. Gocić, M.; Motamedi, S.; Shamshirband, S.; Petković, D.; Ch, S.; Hashim, R.; Arif, M. Soft computing approaches for forecasting reference evapotranspiration. Comput. Electron. Agric. 2015, 113, 164-173. [CrossRef]

25. Zhang, X.; Lv, J.; Dawuda, M.M.; Xie, J.; Yu, J.; Gan, Y.; Zhang, J.; Tang, Z.; Li, J. Innovative passive heat-storage walls improve thermal performance and energy efficiency in Chinese solar greenhouses for non-arable lands. Sol. Energy 2019, 190, 561-575. [CrossRef]

26. Laura, S.; Sumalan, R. Plant growth and development monitoring through integrated sensor systems. For. Biotechnol. 2013, 17, 307-311. Available online: https://www.journal-hfb.usab-tm.ro/romana/2013/Lista\% 20Lucrari\%20PDF/Volum\%2017(1)\%20PDF/59Suciu\%20Laura.pdf (accessed on 28 April 2020).

27. Shamshiri, R.R.; Jones, J.W.; Thorp, K.R.; Ahmad, D.; Man, H.C.; Taheri, S. Review of optimum temperature, humidity, and vapour pressure deficit for microclimate evaluation and control in greenhouse cultivation of tomato: A review. Int. Agrophys. 2018, 32, 287-302. [CrossRef]

28. Jizhang, W.; Lee, W.F.; Ling, P.P. Estimation of Thermal Diffusivity for Greenhouse Soil Temperature Simulation. Appl. Sci. 2020, 10, 653.

29. Chen, L.; Chen, J.; Chen, C. Effect of Environmental Measurement Uncertainty on Prediction of Evapotranspiration. Atmosphere 2018, 9, 400. [CrossRef]

30. Shield, I. Sugar and starch crop supply chains. In Biomass Supply Chains for Bioenergy and Biorefining; Elsevier: Amsterdam, The Netherlands, 2016; pp. 249-269. [CrossRef]

31. Fourati, F. Multiple neural control of a greenhouse. Neurocomputing 2014, 139, 138-144. [CrossRef]

32. Van Straten, G.; Van Willigenburg, G.; Van Henten, E.; Van Ooteghem, E. Optimal Control of Greenhouse Cultivation; CRC Press: London, UK, 2010; p. 326. ISBN 978-1-42-005961-8.

33. Davis, T.W.; Kuo, C.-M.; Liang, X.; Yu, P.-S. Sap Flow Sensors: Construction, Quality Control and Comparison. Sensors 2012, 12, 954-971. [CrossRef]

34. NSW Department of Primary Industries. Computer Control Systems, Sensors and Monitoring Equipment in Greenhouses. Available online: https://www.dpi.nsw.gov.au/agriculture/horticulture/greenhouse/structuresand-technology/computer-control (accessed on 27 April 2020).

35. Powerplants. Paskal Growth Analysis System. Available online: https://powerplants.com.au/controlsystems/paskal-growth-analysis-system (accessed on 27 April 2020).

36. Fernandez-Jaramillo, A.A.; Duarte-Galvan, C.; Contreras-Medina, L.M.; Torres-Pacheco, I.; Romero-Troncoso, R.J.; Guevara-Gonzalez, R.G.; Millan-Almaraz, J.R. Instrumentation in Developing Chlorophyll Fluorescence Biosensing: A Review. Sensors 2012, 12, 11853-11869. [CrossRef] 
37. Murchie, E.H.; Lawson, T. Chlorophyll fluorescence analysis: A guide to good practice and understanding some new applications. J. Exp. Bot. 2013, 64, 3983-3998. [CrossRef]

38. Bartzanas, T.; Fidaros, D.; Baxevanou, C. Precision Modelling of Distributed Greenhouse Climate. In Proceedings of the 8th International Conference on Information and Communication Technologies in Agriculture, Food and Environment (HAICTA), Chania, Greece, 21-24 September 2017.

39. Cola, G.; Mariani, L.; Toscano, S.; Romano, D.; Ferrante, A. Comparison of Greenhouse Energy Requirements for Rose Cultivation in Europe and North Africa. Agronomy 2020, 10, 422. [CrossRef]

40. Zeng, S.; Hu, H.; Xu, L.; Li, G. Nonlinear Adaptive PID Control for Greenhouse Environment Based on RBF Network. Sensors 2012, 12, 5328-5348. [CrossRef]

41. Vanthoor, B.H.E.; Visser, P.H.B.D.; Stanghellini, C.; Henten, E.J.V. A methodology for model-based greenhouse design: Part 2, description and validation of a tomato yield model. Biosyst. Eng. 2011, 110, 378-395. [CrossRef]

42. Su, Y.; Xu, L.; Li, D. Adaptive fuzzy control of a class of MIMO nonlinear system with actuator saturation for greenhouse climate control problem. IEEE Trans. Autom. Sci. Eng. 2016, 13, 772-788. [CrossRef]

43. Nicolosi, G.; Volpe, R.; Messineo, A. An Innovative Adaptive Control System to Regulate Microclimatic Conditions in a Greenhouse. Energies 2017, 10, 722. [CrossRef]

44. Jung, D.-H.; Kim, H.-J.; Kim, J.Y.; Lee, T.S.; Park, S.H. Model Predictive Control via Output Feedback Neural Network for Improved Multi-Window Greenhouse Ventilation Control. Sensors 2020, 20, 1756. [CrossRef] [PubMed]

45. Francik, S.; Kurpaska, S. The Use of Artificial Neural Networks for Forecasting of Air Temperature inside a Heated Foil Tunnel. Sensors 2020, 20, 652. [CrossRef] [PubMed]

46. Chen, J.; Yang, J.; Zhao, J.; Xu, F.; Zhen, S.; Zhang, L. Energy demand forecasting of the greenhouses using nonlinear models based on model optimized prediction method. Neurocomputing 2016, 174, 1087-1100. [CrossRef]

47. Hasni, A.; Taibi, R.; Draoui, B.; Boulard, T. Optimization of greenhouse climate model parameters using particle swarm optimization and genetic algorithms. Energy Proc. 2011, 6, 371-380. [CrossRef]

48. Li, H.-X.; Qi, C. Spatio-Temporal Modeling of Nonlinear Distributed Parameter Systems-A Time/Space Separation Based Approach; Springer: Berlin/Heidelberg, Germany, 2011.

49. Coloşi, T.; Abrudean, M.; Ungurșan, M.L.; Mureșan, V. Numerical Simulation of Distributed Parameter Processes; Springer: Cluj-Napoca, Romania, 2013.

50. Pasgianos, G.D.; Arvanitis, K.G.; Polycarpou, P.; Sigrimis, N.A. A Non-Linear Feedback Technique for Greenhouse Environmental Control. Comput. Electron. Agric. 2003, 40, 153-177. [CrossRef]

51. Rasheed, A.; Na, W.H.; Lee, J.W.; Kim, H.T.; Lee, H.W. Optimization of Greenhouse Thermal Screens for Maximized Energy Conservation. Energies 2019, 12, 3592. [CrossRef]

52. Shen, Y.; Wei, R.; Xu, L. Energy Consumption Prediction of a Greenhouse and Optimization of Daily Average Temperature. Energies 2018, 11, 65. [CrossRef]

53. Chang, W. A modified particle swarm optimization with multiple subpopulations for multimodal function optimization problems. Appl. Soft Comput. 2015, 33, 170-182. [CrossRef]

54. Mostafavi, S.A.; Rezaei, A. Energy consumption in greenhouses and selection of an optimized heating system with minimum energy consumption. Heat Transf. Asian Res. 2019, 48, 3257-3277. [CrossRef]

55. Bennis, N.; Duplaix, J.; Enéa, G.; Haloua, M.; Youlal, H. Greenhouse climate modelling and robust control. Comput. Electron. Agric. 2008, 61, 96-107. [CrossRef]

56. Monje, C.A.; Chen, Y.; Vinagre, B.M.; Xue, D.; Feliu-Batlle, V. Fractional-order Systems and Controls; Springer: London, UK, 2010.

57. Marvuglia, A.; Messineo, A. Using recurrent artificial neural networks to forecast household electricity consumption. Energy Procedia 2012, 14, 45-55. [CrossRef]

58. Mohamed, S.; Hameed, I.A. A GA-Based Adaptive Neuro-Fuzzy Controller for Greenhouse Climate Control System. Alex. Eng. J. 2018, 57, 773-779. [CrossRef]

59. Zhang, D.; Wu, X.; Zhang, C. The application of fuzzy control in greenhouse environment control. Appl. Mech. Mater. 2014, 543-547, 1432-1435. [CrossRef] 
60. Oguntoyinbo, B.; Ozawa, T.; Kawabata, K.; Hirama, J.; Yanagibashi, H.; Matsui, Y.; Kurahashi, A.; Shimoda, T.; Taniguchi, M.; Nishibori, K. SMA (Speaking Mushroom Approach) Environmental Control System Development: Automated Cultivation Control System Characterization. IFAC Proc. Vol. 2013, 46, 340-345. [CrossRef]

61. Thirer, N.; Uchansky, I. An FPGA Based Computer System for Greenhouse Control. Athens J. Sci. 2015, 2, 23-32. [CrossRef]

62. Groener, B.; Knopp, N.; Korgan, K.; Perry, R.; Romero, J.; Smith, K.; Stainback, A.; Strzelczyk, A.; Henriques, J. Preliminary Design of a Low-Cost Greenhouse with Open Source Control Systems. Procedia Eng. 2015, 107, 470-479. [CrossRef]

63. Ibrahim, H.; Mostafa, N.; Halawa, H.; Elsalamouny, M.; Daoud, R.; Amer, H.; Adel, Y.; Shaarawi, A.; Khattab, A.; ElSayed, H. A layered IoT architecture for greenhouse monitoring and remote control. SN Appl. Sci. 2019, 1, 1-12. [CrossRef]

64. Zhang, T.; Li, J.; Li, J.; Wang, L.; Li, F.; Liu, J. Model Embedded DRL for Intelligent Greenhouse Control. In Proceedings of the AAAI-20 Workshop on Artificial Intelligence of Things, New York, NY, USA, 7-8 February 2020; pp. 1-5.

65. Padmanabha, M.; Streif, S. Design and Validation of a Low Cost Programmable Controlled Environment for Study and Production of Plants, Mushroom, and Insect Larvae. Appl. Sci. 2019, 9, 5166. [CrossRef]

66. Stroia, N.; Moga, D.; Muresan, V.; Lodin, A. Estimating Environmental Variables in Smart Sensor Networks with Faulty Nodes. In Proceedings of the 9th International Conference on Smart Cities and Green ICT Systems (SMARTGREENS), Online Streaming, 2-4 May 2020.

(C) 2020 by the authors. Licensee MDPI, Basel, Switzerland. This article is an open access article distributed under the terms and conditions of the Creative Commons Attribution (CC BY) license (http://creativecommons.org/licenses/by/4.0/). 